\title{
Lévy Processes and the Financial Crisis: Can We Design a More Effective Deposit Protection?
}

\author{
Sara Maccaferri (Corresponding author) \\ Department of Mathematics, K.U.Leuven \\ European Commission, JRC Via E. Fermi 2749, 21027 Ispra (VA), Italy \\ Tel: 39-332-785-394 E-mail: sara.maccaferri@jrc.ec.europa.eu \\ Jessica Cariboni \\ European Commission, JRC Via E. Fermi 2749, 21027 Ispra (VA), Italy \\ Tel: 39-332-789-372Ｅ-mail: jessica.cariboni@jrc.ec.europa.eu \\ Wim Schoutens \\ Department of Mathematics, K.U.Leuven Celestijnenlaan 200 B, B-3001, Leuven, Belgium \\ Tel: 32-16-322-027 E-mail: wim.schoutens@wis.kuleuven.be
}

Received: September 28, 2012

doi:10.5430/ijfr.v4n1p5
Accepted: October 25, $2012 \quad$ Online Published: December 16, 2012

URL: http://dx.doi.org/10.5430/ijfr.v4n1p5

\begin{abstract}
Deposit Guarantee Schemes (DGSs) are institutions whose main aim is to provide a safety net for depositors. If a bank fails, depositors will recover their bank deposits up to a certain limit. During the recent financial crisis, DGSs were brought at the centre of the political and financial debate, especially due to the fact that the some DGSs resulted incapable to react to the crisis because of the lack of funds set aside. In this paper we propose to use Lévy processes to simulate the loss distribution of deposits insured by a DGS in case of banks' failure. The simulated distribution can be used to design an effective DGS. By simulating banks' default and the corresponding losses, our model allows defining a target level for the funds to be collected in order to promptly and effectively respond to financial turmoil and protect the citizens. The proposed approach is applied to a sample of Italian banks.
\end{abstract}

Disclaimer: The findings, interpretations, and conclusions expressed in this paper are entirely those of the authors and should not be attributed to the European Commission. Possible errors and omissions are those of the authors.

Keywords: Deposit insurance, Lévy processes, Credit default swap, Bank defaults

\section{Introduction}

Deposit Guarantee Schemes (DGSs hereinafter) are institutions with the main purpose of reimbursing depositors whenever their bank goes into default. If a credit institution fails, a DGS intervenes and pays back the bank deposits up to a certain amount. In order to work properly, the DGS must have at its disposal an adequate amount of funds to cover potential losses, usually set aside by collecting contributions from banks. It is quite well-known that the existence of these institutions leads to a number of benefits (see Basel Committee on Banking Supervision and International Association of Deposit Insurers (2009)): from depositors' point of view, DGSs protect a part of their wealth by reimbursing their deposits; from banking stability perspective, DGSs contribute to strengthen the confidence in the financial sector, thus preventing bank runs, and to create a level playing field, thus avoiding competitive distortions (see for example Garcia (1999) and Cariboni et al (2010)). Moreover, for small failures, DGSs also avoid the state aid.

These schemes are in place in many countries all over the world, like in the US, Canada, Russia, and Australia (Laeven (2008) summarizes the main features of the existing DGSs in the world). In the European Union, Directive 94/19/EC (European Parliament and Council (1994)) and the Amending Directive (European Parliament and Council (2009)) oblige Member States to ensure the existence of at least one or more schemes on their territory and regulate 
some aspects of their functioning. The 2008 global financial crisis brought deposit protection at the centre of the political and financial debate. Since some DGSs have not been able to completely face with bank defaults, some governments have intervened to recapitalize the banking system, as highlighted by the European Commission (2008), and the European Commission (2010) adopted a legislative proposal, with the aim of improving and harmonizing many aspects of the functioning left to the discretion of DGSs up to now.

The academic research on DGSs modeling is well developed and it can be divided into two groups, depending on the way the default event is defined (the paper by De Lisa et al (2011) provides a comprehensive summary of the existing literature). Few studies (Duffie et al (2003) among the others) adopt reduced-form models to estimate fair market premiums, while most studies (Bennett (2002), Kuritzkes et al (2005) and Sironi and Zazzara (2004) for example) estimate banks' default probabilities from market data and they rely on structural credit risk models. A new model, recently developed by De Lisa et al (2011), proposes a novel approach to estimate the loss distributions which explicitly considers the link between deposit insurance and the regulatory framework for capital requirements introduced by Basel II.

This paper proposes a technique to simulate the loss distribution of a banking system. Moreover, based on this distribution, this paper also presents a methodology to design an effective DGS. This methodology aims at:

- Assessing the current level of security provided by DGS current financial endowments;

- Choosing a proper size for the fund such that it can afford a desired level of protection.

More specifically, the methodology can detect those existing DGS which may be underfinanced and might face difficulties in case of failure of its members. On the other side, the simulated loss distribution lets us choose the optimal amount of money the DGS's fund should set aside in order to guarantee a fixed level of protection to its members. Both these issues have become of great importance during the recent financial crisis.

Starting from CDS spreads, we first derive banks' default probabilities by assuming an underlying pricing model; then, we simulate banks' defaults and we finally compute the distribution of losses to be covered by the DGS deriving from the banks' defaults. The novelty of this approach is that, although default probabilities have already been estimated from CDS spreads, this procedure to our knowledge has never been explored in the context of DGSs.

The approach to simulate the fund's losses is similar to that usually adopted to simulate an obligor portfolio's losses. In fact, following a well-recognized approach (Bennett (2002), Kuritzkes et al (2005) and Sironi and Zazzara (2004) among the others), DGSs' funds can be regarded of as portfolios of counterparty risks; these portfolios consist of individual exposures to insured banks, each of which has a small but non-zero probability of causing a loss to the fund.

The procedure adopted to simulate the loss distributions relies on the classical credit risk techniques (see Bluhm et al (2003), Schönbucher (2003) and Schoutens and Cariboni (2009)): defaults occur if the bank's asset value falls below a threshold, asset value processes follow a generic one-factor model and default times are exponentially distributed. A novel approach is proposed to model asset-value processes, which are assumed to follow a generic one-factor Lévy model: as practical examples, results for the one-factor Gaussian model and for the one-factor Shifted Gamma Lévy model are investigated. The approach is applied to a sample of 51 Italian banks accounting for around $60 \%$ of the total amount of eligible deposits and for around 43\% of total assets as of 2006 in Italy.

This paper is organized as follows: Section 2 introduces the main features of the functioning of DGSs and gives an overview of the existing scientific literature on DGSs; Section 3 presents the key issues of the theory of Lévy models; Section 4 describes the methodology applied to build the empirical loss distributions; Section 5 presents the results and Section 6 concludes.

\section{Deposit Guarantee Schemes: Main Features and Rationale}

\subsection{Main Features of Deposit Guarantee Schemes}

In this paragraph we define some key concepts related to DGSs used in the remainder of this paper.

The level of coverage is the level of protection granted by the DGS to depositors in case of default. If a bank fails, the scheme has to pay for every deposit an amount equal to:

$\min \{$ Amount of deposit; Level of coverage\}.

For example, the level of coverage is fixed equal to $€ 100000$ in the EU and to $\$ 250000$ in the US.

Eligible deposits are those deposits eligible for protection by DGSs, i.e. all those classes of deposits which are entitled to be reimbursed by the scheme in case of failure, before the level of coverage is applied. 
Covered deposits are the amount of deposits obtained from eligible deposits after applying the level of coverage: this is the amount to be effectively paid by the scheme in case of failure. (Note 1)

Most DGSs set aside a monetary fund which it is employed in case of default to repay the bank's deposits. The fund is filled up by member banks via contributions paid to the scheme, usually in advance, on a regular basis.

\subsection{Literature Review}

Up to our knowledge, the first mathematical model applied to DGSs has been developed by Merton in his seminal paper (Merton (1977), based on Merton (1974)) and it has subsequently been implemented by Markus and Shaked (1984) and by Ronn and Verma (1986). In this model the fair premium each bank should pay to the scheme is computed by treating the deposit insurance as a put option written on the bank's asset value.

Later on, two main groups of models have been developed: the reduced form models and the structural credit risk models (for a comparison of the two models see, for example, Jarrow and Protter (2004)).

The first class of models defines defaults as stopping times, whose intensities depend upon financial and macroeconomic conditions. The model developed by Duffie et al (2003), for example, applies methods for the pricing of fixed-income securities subject to default risk to compute the fair premia that banks should pay to the DGS. The fair premium for each bank is a function of its short-term credit spread, the expected loss at failure per dollar of protected deposits and the expected loss given default on the bank's debt.

The second class of models considers defaults as events occurring when the bank's asset value falls below a certain threshold, usually correspondent to its liabilities' value.

The model first presented by Bennett (2002) and then reappraised by Kuritzkes et al (2005) aims at building an empirical loss distribution faced by the American DGS (Federal Deposit Insurance Corporation, FDIC hereinafter), used to assess the fund adequacy. Banks' default probabilities are modelled according to the Vasicek (2002) model and loss distributions are built by running Monte Carlo simulations. Bennett (2002) investigates some possible techniques to estimate banks' default probabilities. The first technique relies upon internal models which translate credit ratings into default probabilities. Moreover, logit models are investigated: in these models the log of the odds-ratios is assumed to be linearly related to a number of financial indicators, covering capital adequacy, asset quality, earnings and safety-and-soundness areas. In the paper by Kuritzkes et al (2005) default probabilities are estimated from credit ratings of banks provided by Moody's, Standard \& Poor's and from the internal credit scoring model developed by FDIC.

Sironi and Zazzara (2004) apply a similar approach to the 15 largest Italian listed banks. They estimate the empirical loss distribution and compute risk-based premia that take into account contributions to both scheme's fund expected and unexpected losses. Default probabilities are estimated from Moody's KMV model (see Crosbie (1999)).

Instead of building an empirical loss distribution using Monte Carlo simulations, Dev et al (2006) developed an analytical model to determine the appropriate size of the scheme's fund and the premia banks should pay. They explicitly take into account the banks' liability structure, especially distinguishing between insured and uninsured deposits, and claims senior to deposits.

The model proposed by De Lisa et al (2011) explicitly considers the link that exists between deposit insurance and the regulatory framework for capital requirements introduced by Basel II. A bank goes into default if its obligor's losses exceed its actual capital, which is given by the Basel II regulatory capital plus the excess capital, if any. Banks' default probabilities, and the corresponding losses, are computed according to the Basel II FIRB (Foundation Internal Rating Based) formula and by making use of publicly available regulatory capital information. The impact of systemic risk is included in the model via two sources. The first source depends on the fact that banks have correlated exposures and thus common exposures to the business cycle. The second source depends on the domino effect across the banking system due to linkages between banks produced by the interbank lending market.

\subsection{Motivation of the Work}

Each DGS can be regarded of as a portfolio of counterparty risks (see Bennett (2002), Kuritzkes et al (2005), and Sironi and Zazzara (2004)): this portfolio consists of individual exposures to insured banks, each of which has a small but non-zero probability of causing a loss to the fund. If a bank defaults, it creates a loss to the fund: it is a liquidity shortfall, because depositors will be reimbursed by the DGS. In general, there is a high probability of a small loss to the fund, but there is also a (small) positive probability that the fund will incur large losses stemming from a single large bank failure or from the simultaneous failure of a large number of banks.

Despite the similarities between the DGS and a portfolio of loans, it is clear that the default events are different. The 
defaults on individual loans simply occur when the borrower is unable to afford its payments, while banks fail because of a combination of credit, market and operational risks. Moreover, the failure of a bank is not a sudden event, but is a regulatory one, because only supervisory authorities can declare the default of an institution.

The aim of this paper is to present a methodology to design an effective DGS, with focus on the size of the fund the scheme should set aside; the procedure relies upon the simulated defaults of the banks and on the corresponding loss distribution of the banking system.

This methodology has a twofold scope.

- To assess the current level of security (corresponding to the current size of fund) provided to deposits by DGS current financial endowments. By comparing the DGS current fund size with the simulated loss distribution we can estimate the percentage of losses the fund would be able to cover: this analysis could be of help in detecting those DGS which might be underfinanced and thus might face difficulties in case of its members' defaults.

- To choose a proper target size for the fund such that it can afford a desired level of protection. The desired percentage of losses to be covered is fixed and the corresponding amount the DGS should set aside is estimated from the simulated loss distribution.

Real data on banks' defaults cannot be used to build an empirical loss distribution of the banking system and thus defaults are simulated via statistical models. Following a consolidated approach, a firm-value model is applied to simulate banks' losses: as it will be detailed in Section 4, banks are assumed to default when their asset value processes fall below a certain threshold. Asset values are usually modeled via a one-factor Gaussian model (see Schönbucher (2003) among the others), however, there is a wide consensus that the Gaussian model, though very flexible, fails to reproduce some aspects financial variables usually have; Lévy processes, on the contrary, better reproduce heavy tail distributions' features and the likelihood of many joint default is higher than for the Normal distribution. For comparison purposes, in Section 5, results are presented both for the one-factor Gaussian model and for the one-factor Shifted Gamma Lévy model, a specific Lévy model.

\section{Lévy Processes and Lévy Models}

In this Section we introduce Lévy processes and their main features and we also describe the models which will be used in Section 4 to simulate banks' losses.

Let $\phi(z)$ be the characteristic function of a distribution. If, for every positive integer $n, \phi(z)$ is also the $n$-th power of a characteristic function, we can say that the distribution is infinitely divisible. One can define for every infinitely divisible distribution a stochastic process $X=\left\{X_{t}, t \geq 0\right\}$, called Lévy process, which starts at zero, has stationary and independent increments and such that the distribution of an increment $X_{t+s}-X_{s}$, with $s, t \geq 0$ has $(\phi(z))^{t}$ as characteristic function (see Schoutens (2003), Cont and Tankov (2004) and Schoutens and Cariboni (2009) for more details about the applications of Lévy processes in finance).The function $\psi(z):=\log \phi(z)$ is called the characteristic exponent and it satisfies the following Lévy-Khintchine formula

$$
\psi(z)=i \gamma z-\frac{\varsigma^{2}}{2} z^{2}+\int_{-\infty}^{+\infty}\left(e^{i z x}-1-i z x \mathbb{I}_{\{|x|<1\}}\right) v(d x), \quad z \in \mathbb{R},
$$

where $\gamma \in \mathbb{R}, \varsigma^{2} \geq 0$, and $v$ is a measure on $\mathbb{R} \backslash\{0\}$ such that

$$
\int_{-\infty}^{+\infty}\left(1 \wedge x^{2}\right) v(d x)<\infty .
$$

From the Lévy-Khintchine formula one sees that, in general, a Lévy process consists of three independent parts: a linear deterministic part, a Brownian part, and a pure jump part. The corresponding infinitely divisible distribution is said to have a Lévy triplet $\left[\gamma, \varsigma^{2}, v(d x)\right]$.

The measure $v$ is called the Lévy measure and it dictates how the jumps occur: jumps of sizes in a set $A$ occur according to a Poisson process with parameter

$$
v(A)=\int_{A} v(d x) .
$$

$v(A)$ is thus the expected number of jumps per unit of time whose size belongs to $A$.

\subsection{Generic One-Factor Lévy Models}

In this Section we introduce the generic one-factor Lévy models. Let us choose an infinitely divisible distribution $L$ 
and let $X=\left\{X_{u}, u \in[0,1]\right\}$ and $X_{(i)}=\left\{X_{u}^{(i)}, u \in[0,1]\right\}, i=1, \ldots, M$ be independent and identically distributed Lévy processes such that $X_{I}$ and $X^{(i)}{ }_{1}, i=1, \ldots, M$ follow the law $L$. We further assume that $\mathbb{E}\left[X_{1}\right]=0$ and $\operatorname{var}\left(X_{1}\right)=1$ and from this it can be shown that $\operatorname{var}\left(X_{\nu}\right)=u$. Let $\rho \in(0,1)$; the generic one-factor Lévy model for the asset value of the $i$-th bank at time $t$ is of the form

$$
A_{i}(t)=X_{\rho}+X_{1-\rho}^{(i)}, \quad i=1, \ldots, M .
$$

Each $A_{i}(t)$ has by the stationary and independent increments property the same distribution $L$ with distribution function $F_{X I}$, where $F_{X u}$ is the distribution function of $X_{u}, u \in[0,1]$. As a consequence, $\mathbb{E}\left[A_{i}(t)\right]=0$ and $\operatorname{var}\left(A_{i}(t)\right)=1$. Furthermore, it can be easily proved that the asset values of any two banks $i$ and $j$, with $i \neq j$, are correlated with linear correlation coefficient $\rho$.

\subsection{One-factor Gaussian Model}

The Brownian motion is a particular Lévy process with Lévy triplet $\left[\mu, \sigma^{2}, 0\right]$. The generic one-factor Lévy model built with a Brownian motion coincides with the Vasicek (2002) model. The generic one-factor Lévy model in this case can be rewritten as:

$$
A_{i}(t)=\sqrt{\rho} Y+\sqrt{1-\rho} X_{i}, \quad i=1, \ldots, M,
$$

where $Y$ and $X_{i}, i=1, \ldots, M$ are independent normally distributed random variables with zero mean and variance $1, \rho$ $\in(0,1)$ and $M$ is the number of banks (see Schönbucher (2003)). The variable $Y$ is a common factor and can be interpreted as a systematic risk factor, common to all banks, while $X_{i}$ is an idiosyncratic noise component and it represents the firm specific risk factor; the parameter $\rho$ is the correlation factor. This model assumes that the vector of $\mathrm{M}$ asset values $A_{i}(t)$ is multivariate standard Normal distributed:

$$
\left[A_{i}(t)\right] \sim \mathcal{N}(\mathbf{0}, \mathbf{\Sigma}), \text { where } \Sigma_{i j}= \begin{cases}1 & i=j \\ \rho & i \neq j\end{cases}
$$

\subsection{One-factor Shifted Gamma Lévy Model}

We recall that the density function of the gamma distribution Gamma(a,b) with $\mathrm{a}>0, \mathrm{~b}>0$ has the following expression:

$$
f(x)=\frac{b^{a}}{\Gamma(a)} x^{a-1} e^{-x b}, x>0
$$

and the corresponding characteristic function is given by

$$
\phi(z)=\frac{1}{\left(1-\frac{i z}{b}\right)^{a}}, \quad z \in \mathbb{R}
$$

Table 1 reports the moments of the $\operatorname{Gamma}(a, b)$ distribution.

It is straightforward to prove that the characteristic function of the $\operatorname{Gamma}(a, b)$ distribution is infinitely divisible.

Let us consider a unit-variance gamma process $G=\left\{G_{u}, u \geq 0\right\}$ with parameters $a>0$ and $b=\sqrt{a}$ such that $\mathbb{E}\left[G_{l}\right]=\sqrt{a}$ and $\operatorname{var}\left(G_{l}\right)=1$. As a driving Lévy process we consider the Shifted Gamma process:

$$
X_{u}=\sqrt{a} u-G_{u}, \quad u \in[0,1] .
$$

The (financial) interpretation in terms of asset value is that there is a deterministic up trend, given by $\sqrt{a} u$ with random downward shocks $G_{u}$ (see Albrecher et al (2006)).

The one-factor shifted Gamma Lévy model is given by Equation (1), where $X_{\rho}, \rho \in(0,1)$, and $\left\{X_{1-\rho}^{(i)}, \rho \epsilon(0,1)\right\} i=$ $1, \ldots, M$ are independent standardized Shifted Gamma processes, defined as

$$
X_{\rho}=\sqrt{a} \rho-G_{\rho} \quad \text { and } \quad X_{1-\rho}^{(i)}=\sqrt{a}(1-\rho)-G_{1-\rho} .
$$

By construction, each $A_{i}(t)$ has the same distribution as $X_{l}$.

\section{Research Methodology}

The aim of the present paper is to propose a methodology to design an effective DGS and to size its fund. As already 
mentioned, this methodology mainly relies upon the simulated loss distribution of the banking system; in this Section we describe the main steps of the simulation, which can be summarized as follows:

1) Estimate banks' default probabilities from CDS spreads market data, where available, and from risk indicators elsewhere. These default probabilities are used to calibrate the default intensities of the banks' default time distributions;

2) Draw realizations of the banks' asset value processes, assuming a firm-value approach;

3) From the asset values draws, compute the corresponding default times;

4) Evaluate the corresponding amount of covered deposits and the loss distributions.

\subsection{Estimating Banks’ Default Probabilities}

We propose to estimate banks' default probabilities from the corresponding CDS market data because the CDS premia are among the best measures of the market pricing of credit risk currently available. This is mainly due to standardized contracts and the relatively high liquidity in the market (Raunig and Scheicher (2009)). Unfortunately, CDS contracts are written only on a very limited number of banks: for example in 2006, CDS contracts were written on only around 40 European banks, of which only 4 Italian banks.

In order to enlarge the sample, we make use of the entire set of European banks underlying a CDS contract and we establish a relation between default probabilities $D P$ and a set of financial indicators:

$$
D P=h \text { (financial indicators) }
$$

We apply this formula to the sample of banks representing the banking system we want to investigate, in order to have an estimate of the default probabilities for the entire system of banks. Financial indicators are computed from balance sheet data and thus are potentially available for all banks.

In developing this approach, particular attention should be paid to the differences between the risk-neutral and the historical default probabilities (labeled $D P^{Q}$ and $D P^{P}$ respectively). Mathematically speaking, the risk-neutral probability is the probability measure under which the current market price of a generic contingent claim is equal to the discounted expected value of its future cash flows (Björk (1998)). The corresponding risk-neutral default probabilities are used for pricing because they build an extra return, called risk premium, to compensate market participants for the risk they are bearing (Hull et al (2005)). Historical default probabilities are probabilities calculated from historical data, and they are not used for pricing purposes. The two probabilities settings lead to different default probabilities estimates. Historical default probabilities are usually smaller than risk-neutral ones, because the latter reflect the risk premia required by market participants to take on risks associated with default (Duffie and Singleton (2003)).

It is important to stress why we consider both the risk-neutral and the historical probability measures. According to literature practices (Chan-Lau (2006)), we use financial indicators, built from balance sheet variables, to estimate banks' default probabilities. Since balance sheet data are backward looking by construction and they give information only on what has happened in the past (Huang et al (2009)), the correct probability to be associated to them is the historical default probability. Risk-neutral probabilities, on the contrary, are forward looking measures.

Since in this paper we deal with both default probabilities, depending on the set of available data for each bank, we build a map which let us move from one probability measure to the other. The following steps are applied to estimate the default probabilities.

1) Estimate European banks' risk-neutral default probabilities from CDS spreads for the sample of European banks.

2) Using data on the European banks underlying CDS contracts, calibrate a map $f$ between risk neutral and historical default probabilities:

$D P^{P}=f\left(D P^{Q}\right)$.

3) Using data on the European banks underlying CDS contracts, estimate a model $h$ between financial indicators and historical default probabilities:

$D P^{P}=h$ (financial indicators).

4) Using balance sheet data of the sample of banks we want to investigate, apply the model $h$ estimated in step 3 to get an estimate of their historical default probabilities.

5) Estimate risk-neutral default probabilities by applying the reverse map $f^{-1}$ introduced in step 2 


$$
D P^{Q}=f^{-1}\left(D P^{P}\right)
$$

and estimate the intensity parameters $\lambda_{i}$ for every bank from the risk-neutral default probabilities.

The steps listed above are summarized in Figure 1. The risk-neutral default probabilities will be used to calibrate the term structure of the banks'default probabilities.

\subsubsection{Estimating the Banks' Default Probabilities from CDS}

A Credit Default Swap (for a detailed description refer to Duffie and Singleton (2003) and to Schoutens and Cariboni (2009)) is an over-the-counter bilateral agreement where the protection buyer transfers the credit risk of a reference entity to the protection seller for a determined amount of time $T$. The buyer of this protection makes predetermined payments to the seller. The payments continue until the maturity date $T$ of the contract, or until default occurs, whichever is earlier. In case of default of the reference entity, the protection seller pays to the protection buyer a determined amount. The CDS spread $c$ is the yearly rate paid by the protection buyer to enter a CDS contract against the default of a reference entity, reflecting the riskiness of the underlying credit.

We assume in our model that the default time of the $i$-th bank $\tau_{i}$ is exponentially distributed with intensity parameter $\lambda_{i}, \tau_{i} \sim \mathcal{E}\left(\lambda_{i}\right)$. The corresponding term structure of the cumulative risk-neutral default probability for the $i$-th bank, $p_{i}(t)$, has the following expression (Schoutens and Cariboni (2009)):

$$
p_{i}(t):=P^{Q}\left[\tau_{i} \leq t\right]=1-e^{-\lambda_{i} t} .
$$

It can be easily shown (see Duffie and Singleton (2003), Schönbucher (2003) and Schoutens and Cariboni (2009)) that under these hypotheses the spread $c_{i}$ for the $i$-th bank is equal to:

$$
c_{i}=\left(1-R_{i}\right) \lambda_{i}
$$

In this work we make use of the 2006 daily 5 years-CDS spreads of 40 European banks, provided by Bloomberg (Note 2); we also assume a recovery rate $R_{i}$ constant for all banks and equal to $40 \%$. Starting from market data on CDS, we can compute for every bank $i$ the intensity parameters $\lambda_{i}$ by inverting Equation (5). We then compute the corresponding one-year risk neutral default probability, labeled as $D P^{Q}{ }_{i}$ by setting in Equation (4) $t=1$ :

$$
D P_{i}^{Q}:=P^{Q}\left[\tau_{i} \leq 1\right]=p_{i}(t)=1-e^{-\frac{c_{i}}{1-R_{i}}}
$$

\subsubsection{Building a Map between Risk-neutral and Historical Probabilities}

To build a map between historical and risk-neutral default probabilities we work by rating classes, in order to exploit historical default probabilities available from Moody's. Following Hull et al (2005), we estimate for every rating class the one-year historical default probabilities, labeled $D P^{P}$, from statistics on average cumulative global default yearly rates published by Moody's (Emery et al (2008)). In its annual reports, Moody's provides time-series of the yearly historical firms default probabilities grouped by rating classes. Starting from these data, we estimate the corresponding rating classes' historical default probabilities $D P^{P}$, following the procedure described in Bluhm et al (2003). Every rating class (and every historical default probability) is associated with a risk-neutral default probability equal to the average risk-neutral default probability of all the banks in that class. For example, focusing on the rating class Aaa, the corresponding one-year risk-neutral default probability, labeled $D P^{Q}$ Aaa, is computed as follows:

$$
D P_{\text {Aaa }}^{Q}=\frac{1}{n_{\text {Aaa }}} \sum_{i \in \text { Aaa }} D P_{i}^{Q},
$$

where $n_{\text {Aaa }}$ is the number of banks with a rating score equal to Aaa and $D P^{Q}{ }_{i}$ is the risk-neutral default probability of the $i$-th bank with the given rating (we gathered rating scores for 36 out of 40 European banks from Moody's web-site). $D P^{Q}{ }_{i}$ has been computed according to Equation (6). This procedure let us attain the one-to-one correspondence between the historical and risk-neutral default probabilities reported in Table 2.

From this correspondence we want to infer a continuous and closed-form map to move from one probability measure to the other:

$$
D P^{P}=f\left(D P^{Q}\right), f:[0,1] \rightarrow[0,1]
$$

The function $f(\cdot)$ must be convex because $D P^{Q} \geq D P^{P}$ and must satisfy the constraint $f(0)=0$ (Note 3) (see Berg (2010)). A suitable expression for $f$ is thus

$$
f(x)=e^{x^{a}}-1 .
$$


We calibrate the model by minimizing the Root Mean Square Error: according to this procedure, the optimal parameter is $\mathrm{a}=1.39$. Figure 2 presents the results of the calibration exercise. The dots are the points in Table 2; The continuous line is the map of Equation (7) calibrated on the same set.

Using the map $f$, from the risk-neutral default probabilities $D P^{Q}{ }_{i}$ computed in Equation (6) we can estimate the one-year historical default probabilities $D P^{P}{ }_{i}$ of the 40 European banks in our sample:

$D P_{i}^{P}=f\left(D P_{i}^{Q}\right)$.

4.1.3 Building a Map between Risk Indicators and Historical Default Probabilities

In this step we would like to build a model which links a set of financial indicators with the historical default probabilities $D P^{P}$ :

$$
D P^{P}=h \text { (financial indicators). }
$$

To achieve this objective we investigate linear models:

$$
D P^{P}=\mathrm{X} \beta+\epsilon
$$

between the historical default probabilities estimated in Section 4.1.2 and a set of financial indicators $\mathbf{X}$. In literature there exists a number of possible financial indicators; in this paper we have restricted our attention to the indicators mentioned in the proposal adopted by the European Commission to compute risk-based contributions (European Commission (2010) and Joint Research Centre of the European Commission (2009)). Risk indicators and balance sheet data as of 2006 have been gathered by Bankscope database. (Note 4)

Among all possible choices of indicators, the set of indicators that best explains the $D P^{P}$ result to be, in the least squares sense, the ones listed in Table 3.

The $p$-value of this regression is $5.2 \%$. The model we adopt to estimate historical default probabilities is thus

$$
\left.D P^{P}=h \text { (financial indicators }\right)=\mathbf{X} \hat{\beta},
$$

where $\hat{\beta}$ is the least squares estimate of $\beta$.

\subsubsection{Estimating Historical and Risk-neutral Default Probabilities}

We make use of the balance sheet data of the system of banks under investigation to compute the indicators listed in Table 3 and we apply Equation (10) to estimate the corresponding historical default probabilities.

We then apply the inverse of the map $f$ described by Equation (7) to the obtained historical default probabilities and we get an estimate of the one-year risk-neutral default probabilities $D P^{Q}{ }_{i}$.

Following the approach presented in Section 4.1.1, we assume all Italian banks to have the term structure default probability described by Equation (4); under this assumption, we get default intensity $\lambda_{i}$ estimates:

$$
\lambda_{i}=-\ln \left(1-D P_{i}^{Q}\right) \text {. }
$$

Default intensity parameters are among the inputs of the loss distribution' simulation (see Section 4.3).

\subsection{Simulating Banks' Defaults}

In order to build the empirical loss distribution of the scheme's fund, we must define what we mean by default. In the general case of a credit portfolio, a loss occurs if a borrower defaults. In the specific case of a DGS, a loss occurs if an insured bank fails, thus triggering a fund's payout, as assumed for example by Sironi and Zazzara (2004). In this framework we assume that the $i$-th bank goes into default when its asset value $A_{i}(t)$ falls below a certain threshold $K_{i}(t)$. Bank's asset values are modeled via the two generic one-factor Lévy models presented in Sections 3.2 and 3.3. In both cases we draw realizations of the models and we compute the corresponding default times as follows. In order to match default probabilities under this model with the term structure of default probabilities defined in Equation (4), we have to set $K_{i}(t)=F_{X I}^{(-l)}\left(p_{i}(t)\right)$ :

$$
P\left[A_{i}(t) \leq K_{i}(t)\right]=P\left[A_{i}(t) \leq F_{X_{1}}^{(-1)}\left(p_{i}(t)\right)\right]=F_{X_{1}}\left(F_{X_{1}}^{(-1)}\left(p_{i}(t)\right)\right)=p_{i}(t) .
$$

From the above relationship, the default time $\tau_{i}$ of the $i$-th bank then equals:

$$
\tau_{i}=p_{i}^{(-1)}\left(F_{X_{1}}\left(A_{i}\right)\right)=-\frac{\ln \left(1-F_{X_{1}}\left(A_{i}\right)\right)}{\lambda_{i}}
$$

where $\lambda_{i}$ is the default intensity of the default probability term structure (Equation (4)), and $A_{i}$ is a realization of the asset value process $A_{i}(t)$. In the case of the one-factor Gaussian model, Equation (11) becomes 


$$
\tau_{i}=p_{i}^{(-1)}\left(\Phi\left(A_{i}\right)\right)=-\frac{\ln \left(1-\Phi\left(A_{i}\right)\right)}{\lambda_{i}}
$$

where $\Phi$ is the cumulative distribution function of the standard Normal distribution. In the case of the one-factor Shifted Gamma Lévy model we have to compute the distribution function of $X_{1}$. The distribution function of $X_{1}, F_{X I}$, can be easily obtained from the Gamma distribution function:

$$
F_{X_{1}}(x)=P\left[X_{1} \leq x\right]=P\left[\sqrt{a}-G_{1} \leq x\right]=1-P\left[G_{1}<\sqrt{a}-x\right]=1-F_{\Gamma}(\sqrt{a}-x),
$$

where $F_{\Gamma}$ is the distribution function of a $\operatorname{Gamma}(a, \sqrt{a})$ random variable. Equation (11) becomes:

$$
\tau_{i}=p_{i}^{(-1)}\left(F_{X_{1}}\left(A_{i}\right)\right)=-\frac{\ln \left(F_{\Gamma}\left(\sqrt{a}-A_{i}\right)\right)}{\lambda_{i}}
$$

Without loss of generality, in the following we will consider $a=1$.

\subsection{Generating the Empirical Distribution of the Portfolio Loss}

We assume that when a bank failure occurs, the fund has to pay back deposits of that bank. The exposure at default $E A D_{i}$ is assumed to be equal to the amount of covered deposits held by that bank and thus the loss the fund suffers from is

$$
L_{i}=E A D_{i} *\left(1-R_{i}\right), \quad R_{i}=40 \%
$$

The total loss hitting the fund is estimated by aggregating individual bank losses.

The numerical simulation to build the empirical distribution of the fund's loss is based on the following main steps:

1) Calibration of the default intensities $\lambda_{i}$ by assuming all banks to have the risk-neutral default probability term structure described by Equation (4). From CDS spreads market data, default intensities are estimated by inverting Equation (5). For all the other banks default intensities are calibrated from the default probabilities estimated from risk indicators, as detailed in Section 4.1.

2) Drawing $M$ realizations of the asset value process $A_{i}(t)$, according to the models described in Section 4.2.

3) Estimation of the default times $\tau_{i}$ from Equations (12) and (13), using the $A_{i}$ and $\lambda_{i}$ obtained in steps 2 and 1 respectively.

4) Simulation of the loss distribution: if $\tau_{i} \leq T$, the bank defaults and the funds pays out an amount equal to $L_{i}$ given by Equation (14).

In this exercise $N=100000, \rho=70 \%$ and $T=1$ year. The sample comprises $M=51$ Italian banks, accounting for $60 \%$ of the total amount of eligible deposits, for around $70 \%$ of covered deposits and for $43 \%$ of total assets as of 2006 . Data on deposits are estimated from accounting data (Bankscope), from Eurostat and from Joint Research Centre of the European Commission (2011).

\section{Results}

In this Section we want to present the results of the simulations described in Section 4. The main results are presented in Section 5.1 and in Section 5.2. Section 5.3 develops an additional analysis focusing on a legislative proposal adopted by the European Commission (see European Commission (2010)).

\subsection{One-factor Gaussian Model}

The two histograms in Figure 3 plot the empirical loss distributions of our reference banking system when the banks' underlying asset-value process follows a one-factor Gaussian model. Figure 3(a) shows the empirical loss distribution of the whole sample of Italian banks. Figure 3(b) shows the conditional loss distribution of the sample, i.e. the loss distribution when at least one bank has failed.

Due to scaling problems we also report the corresponding loss distributions in Table 4. According to Table 4(a), the probability that at least one bank in the sample goes into default is equal to $4.15 \%$.

The simulated loss distribution can be used to evaluate the current level of security provided by DGSs. For example, the European Commission (2010) has suggested a target fund equal to $2 \%$ of the amount of eligible deposits. Rescaled on our sample, such a designed fund would have $€ 7.7$ billion at its disposal. If we compare this amount with the loss distribution shown in Table 4(a), we can conclude that such a designed Italian DGS is able to cover up to $98.81 \%$ of its potential losses. (Note 5) The corresponding loss distributions are shown in Figure 4 and relevant 
percentiles are reported in Table 5: according to these figures, the probability that the DGS goes into default is around $1.19 \%$ (see Table 5(a)).

The simulation procedure described in Section 4 can be also applied to choose the "optimal" size of the fund the DGS should set aside. A political decision, for example, could require a DGS to be able to cover losses with size occurring up to a determined probability (i.e. up to a certain percentile of the loss distribution). By using the simulated loss distribution and fixing a determined level of protection, the corresponding target size can be derived. Results are shown in Figure 5. The x-axis plots the target level's sizes as a percentage of eligible deposits, while the $y$-axis plots the corresponding percentage of potential banks' losses covered; the dotted line corresponds to the setting analysed so far (i.e. target level equal to $2 \%$ of eligible deposits). If, for example, the DGS were required to cover at least $99 \%$ of the losses, the fund should set aside a fund equal to $3.2 \%$ of the amount of eligible deposits.

\subsection{One-factor Shifted Gamma Lévy Model}

We now present the results when asset-value processes follow a one-factor Shifted Gamma Lévy model. The two histograms in Figure 6 plot the empirical loss distributions of the banking system. Figure 6(a) shows the empirical loss distribution of the whole sample, while Figure 6(b) shows the corresponding conditional loss distribution.

Following the approach developed in Section 5.1, we report the loss distributions in Table 6. According to Table 6(a), the probability that at least one bank goes into default now slightly increases, from $4.15 \%$ of the previous simulation to $4.91 \%$. Moreover, it is evident that tails are shifted to the right: by comparing high percentiles $\left(99.9^{\text {th }}\right.$ and higher) in Table 4(a) and in Table 6(a), the size of losses occurring with small probabilities is higher for the one-factor Shifted Gamma Lévy model than for the Gaussian model.

We now consider the effects of the protection afforded by the DGS designed according to European Commission (2010). If we compare the target at its disposal with the loss distribution shown in Table 6(a), we can conclude that such a designed Italian DGS is able to cover up to $99.17 \%$ of its potential losses. (Note 6) The corresponding loss distributions are shown in Figure 7 and the figures corresponding to the most relevant percentiles are reported in Table 7: according to these figures, the probability that the DGS goes into default is around $0.83 \%$ (see Table 7(a)).

We replicate the exercise described in Section 5.2 to seek the "optimal" size of the fund the DGS should set aside. Results are shown in Figure 8.

\subsection{Simulation over 10 Years}

Using the model described in Section 4, we have investigated the implications of the adoption of the European Commission proposal for a new Directive on DGSs (see European Commission (2010)). According to this document, DGSs should move to an ex-ante financing mechanism, protect only certain classes of deposits and the fund should reach within 10 years a target level equal to $2 \%$ of the amount of eligible deposits. We have run the simulations $N=100000$ times assuming the asset value to follow a one-factor Gaussian model and we have simulated the fund's behaviour over the transition period $T$ equal to 10 years. During this period, the size of the fund can fall below zero, but at the end of the transition period $T$ it must be positive; if not, the DGS is assumed to be in default. Figure 9 shows three possible fund's paths: the paths labelled with dots and crosses represent the cases where the scheme does not default, even if, in one case (dots) the fund falls below zero during the transition period; the path labelled with squares, on the contrary, represents the case where the scheme defaults, because at the end of the transition period the fund is negative.

Following the approach of Section 5.1 and of Section 5.2, we first present the banking system empirical loss distribution. The two histograms in Figure 10 plot the unconditional (Figure 10(a)) and conditional (Figure 10(b)) empirical loss distributions of the banking system.

Distributions are also reported in Table 8: according to the figures in Table 8(a), the probability that at least one bank goes into default is equal to $22.38 \%$ (Note 7 ).

The fund's loss distributions are shown in Figure 11 and the most relevant percentiles are reported in Table 9. According to these figures, the probability that the DGS goes into default is around $9.71 \%$ (see Table 9(a)).

The simulation procedure described in Section 4 can again be applied to seek the "optimal" size of the fund the DGS should set aside by varying the size of the fund over a wide range, i.e. from $1 \%$ to $50 \%$ and results are shown in Figure 12. If, for example, we want a target size which could cover up to $95 \%$ of the losses, the fund should fix a target level equal to $6.6 \%$ of eligible deposits. 


\subsection{Sensitivity to Results}

This Section investigates the sensitivity of our estimates to the variation of the correlation factor $\rho$, which has been fixed equal to $70 \%$ in the previous analysis.

We let the correlation factor vary between $10 \%$ and $90 \%$ and we compute, for each value, the corresponding optimal fund size necessary to cover up to two fixed percentages of the losses, namely $99 \%$ and $99.95 \%$. Results are shown in Figure 13 and Figure 14. The comparisons of the two Figures show the effects of the correlation and of the tails of the distributions. Figure 13 corresponds to a "small" percentile: the target size decreases when the correlation factor increases and in general values referred to the Gaussian model are always higher than those related to the Lévy model. Figure 14, on the contrary, refers to a "high" percentile: here the target size increases when the correlation factor increases and in general values referred to the Lévy model are always higher than those related to the Gaussian model.

\section{Conclusions}

This article has investigated a possible technique to design an effective DGS. We have focused in particular on the empirical loss distribution of the fund, as it can be used to assess the level of security provided to depositors by the fund and to choose a proper target size for the fund. The empirical loss distribution has been gathered by simulating banks' defaults and the corresponding losses potentially hitting the system.

The procedure adopted to simulate the loss distributions has relied on classical credit risk techniques. The following assumptions hold: defaults occur if the bank's asset-value has fallen below a threshold, asset-value processes follow a generic one-factor model and default times are exponentially distributed. A novel approach has been proposed to model asset-value processes and to estimate banks' default probabilities. Asset-value processes have been assumed to follow a generic one-factor Lévy process and in particular the one-factor Gaussian model and the one-factor Shifted Gamma Lévy model have been investigated. Moreover, a novel approach has been proposed to estimate banks' default probabilities, which are inferred from CDS spreads, because they are regarded of as among the best measures of the market pricing of credit risk currently available. This procedure is quite common in literature, but to our knowledge it has never been explored in the context of DGS.

Our approach has been applied to a sample of Italian banks accounting for $60 \%$ of the amount of eligible deposits and for around $43 \%$ of total assets as of 2006 . According to our results, a DGS with a target fund equal to $2 \%$ of the amount of eligible deposits at its disposal could cover up to $98.81 \%$ of its potential losses, in case the underlying asset-value process follows a one-factor Gaussian model. If the DGS wanted to set aside a fund capable to cover up to $99 \%$ of its potential losses, it should raise its fund up to $3.2 \%$ of the amount of eligible deposits. If we assume asset-value processes to follow a one-factor Shifted Gamma Lévy model, the corresponding DGS could cover losses up to $99.17 \%$ of its potential losses.

\section{References}

Albrecher H, Ladoucette S., \& Schoutens W. (2006). A Generic One-Factor Lévy Model for Pricing Synthetic CDOs. In Fu M, Jarrow R, Yen J, \& Elliott R (Eds.), Advances in Mathematical Finance (pp 259-278). Birkhäuser, Boston.

Basel Committee on Banking Supervision and International Association of Deposit Insurers. (2009). Core Principles for Effective Deposit Insurance System. [Online] Available: http://www.bis.org/publ/bcbs156.pdf (September 6, 2011)

Bennett RL. (2002). Evaluating the Adequacy of the Deposit Insurance Fund: a Credit Risk Modeling Approach. FDIC Working Paper.

Berg T. (2010). From Actual to Risk-neutral Default Probabilities: Merton and Beyond. J Credit Risk, 6(1), $55-86$.

Björk T. (1998). Arbitrage Theory in Continuous Time. Oxford University Press.

Bluhm C, Overbeck L., \& Wagner C. (2003). An Introduction to Credit Risk Modeling. Chapman \& Hall/CRC, Boca Raton.

Cariboni J, Joossens E., \& Uboldi A. (2010). The Promptness of European Deposit Protection Schemes to Face Banking Failures. J Bank Regul, 34(4), 788-801.

Chan-Lau J. (2006). Fundamentals-Based Estimation of Default Probabilities: a Survey. Working Paper 149, IMF.

Cont R., \& Tankov P. (2004). Financial Modelling with Jump Processes. Chapman and Hall/CRC, Boca Raton.

Crosbie P. (1999). Modeling Default Risk. Tech. rep., KMV Corporation, San Francisco. 
De Lisa R., Zedda S., Vallascas F., Campolongo F., \& Marchesi M. (2011). Modeling Deposit Insurance Scheme Losses a Basel II Framework. J Financ Serv Res, 4(3), 123-141.

Dev A., Li S., \& Wan Z. (2006). An Analytical Model for the FDIC Deposit Insurance Premium, Available at SSRN. Duffie D., \& Singleton K.J. (2003). Credit Risk. Princeton Series in Finance.

Duffie D., Jarrow R., Purnanandam A., \& Yang W. (2003). Market Pricing of Deposit Insurance. J Financ Serv Res, 24(2-3), 93-119.

Emery K., Ou S., Tennant J., Kim F., \& Cantor R. (2008). Corporate Default and Recovery Rates, 1920-2007. Moody's Global Corporate Finance.

European Commission. (2008). Report from the Commission - State Aid Scoreboard Autumn 2008 Update. [Online] Available: http://ec.europa.eu/competition/state_aid/studies_reports/archive/2008_autumn_en.pdf(October 26, 2011)

European Commission. (2010). Proposal for a Directive of the European Parliament and of the Council on Deposit Guarantee $\quad$ Schemes. [Online] Available: http://ec.europa.eu/internal_market/bank/docs/guarantee/20100712_proposal_en.pdf (October 12, 2010)

European Parliament and Council. (1994). Directive 94/19/EC of the European Parliament and of the Council of 30 May 1994 on deposit-guarantee schemes. [Online] Available: http://eur-lex.europa.eu/LexUriServ/LexUriServ.do?uri=CELEX:31994L0019:EN:HTML (October 12, 2010)

European Parliament and Council. (2009). Amending Directive 94/19/EC on Deposit-Guarantee Schemes as Regards the Coverage Level and the Payout Delay. [Online] Available: http://eur-lex.europa.eu/LexUriServ/LexUriServ.do?uri=OJ:L:2009:068:0003:0007:EN:PDF (October 12, 2010)

Fondo Interbancario di Tutela dei Depositi. (2006). Statuto e Regolamento. [Online] Available: http://www.fitd.it/normative/stat_reg/statuto_regolamento.pdf (March 16, 2011)

Garcia G. (1999). Deposit Insurance: a Survey of Actual Best Practices. Working Paper 54, IMF.

Huang X., Zhou H., \& Zhu H. (2009). A Framework for Assessing the Systemic Risk of Major Financial Institutions. $J$ Bank Financ, 33(11), 2036-2049.

Hull J., Predescu M., \& White A. (2005). Bond Prices, Default Probabilities and Risk Premiums. J Credit Risk, 1(2), 53-60.

Jarrow R., \& Protter P. (2004). Structural versus Reduced Form Models: a New Information Based Perspective. $J$ Invest Manag, 2(2), 1-10.

Joint Research Centre of the European Commission. (2009). Possible Models for Risk-based Contributions to EU Deposit Guarantee Schemes. [Online] Available: http://ec.europa.eu/internal_market/bank/docs/guarantee/2009_06_risk-based-report_en.pdf (October 12, 2010)

Joint Research Centre of the European Commission. (2011). JRC Report under Article 12 of Directive 94/19/EEC. [Online] Available: http://ec.europa.eu/internal_market/bank/guarantee/index_en.htm (March 16, 2011)

Kuritzkes A., Schuermann T., \& Weiner S. (2005). Deposit Insurance and Risk Management of the US Banking System: What is the Loss Distribution Faced by FDIC? J Financ Serv Res, 27(3), 317-342.

Laeven L. (2008). Deposit Insurance around the World: Issues of Design and Implementation. MIT Press, chap Pricing of Deposit Insurance.

Markus A., \& Shaked I. (1984). The Valuation of FDIC Deposit Insurance Using Option-Pricing Estimates. $J$ Money Credit Bank, 16(4), 44-460.

Merton R. (1974). On the Pricing of Corporate Debt: the Risk Structure of Interest Rates. J Financ, 29(2), 449-470.

Merton R. (1977). An Analytical Derivation of the Cost of Deposit Insurance and Loan Guarantees - an Application of Modern Option Pricing Theory. J Bank Financ, 1, 3-11.

Raunig B., \& Scheicher M. (2009). Are Banks Different? Evidence from the CDS Market. Working Paper 152, Oesterreichische Nationalbank.

Ronn E., \& Verma A. (1986). Pricing Risk-Adjusted Deposit Insurance: an Option-Based Model. J Financ 41(4), 871-895.

Schönbucher P.J. (2003). Credit Derivatives Pricing Models. Wiley, UK.

Schoutens W. (2003). Lévy Processes in Finance: Pricing Financial Derivatives. Wiley, UK.

Schoutens W., \& Cariboni J. (2009). Lévy Processes in Credit Risk. Wiley, UK. 
Sironi A., \& Zazzara C. (2004). Applying Credit Risk Models to Deposit Insurance Pricing: Empirical Evidence from the Italian Banking System. J Int Bank Regul, 6(1), 10-32.

Vasicek O.A. (2002). The Distribution of Loan Portfolio Value. Risk.

\section{Notes}

Note 1 . The following example will clarify the relationships between the level of coverage, eligible and covered deposits. Consider a DGS with only one member bank. The bank has 3 deposits, A, B, and C. Suppose the sizes of the deposits are, respectively, $€ 85000$ for deposit $\mathrm{A}, € 75000$ for deposit $\mathrm{B}$, and $€ 20000$ for deposit $\mathrm{C}$. Moreover, suppose that deposit $\mathrm{A}$ is not eligible for protection, and that the level of coverage is $€ 50000$. The amounts of eligible and covered deposits are:

Amount of eligible deposits $=€(75000+20000)=€ 95000$

Amount of covered deposits $=€(50000+20000)=€ 70000$.

Note 2. Bloomberg has been accessed from Bocconi University, $19^{\text {th }}$ November 2010.

Note 3. We should also take into account the second constraint $f(1)=1$. As our data are all close to zero and default probabilities will be unlikely to assume values close to one, we relax the second constraint.

Note 4. Bankscope has been accessed from Bocconi University, Milan, $19^{\text {th }}$ November 2010.

Note 5. Although ex-post financed, the Italian DGS has a virtual target fund at its disposal, whose size is equal to $0.8 \%$ of the amount of covered deposits (see Fondo Interbancario di Tutela dei Depositi (2006)). The virtual target fund, rescaled on our sample, is equal to $€ 2.22$ billion and it can cover up to $97.65 \%$ of the fund's potential losses for the one-factor Gaussian model.

Note 6. If we consider the virtual target fund the Italian DGS has at its disposal ( $0.8 \%$ of covered deposits) and if we rescale it on our sample, we can conclude that such a fund can cover up to $97.93 \%$ of the potential losses for the one-factor Shifted Gamma Lévy model.

Note 7. Recall that, during the transition period, the DGS collects annual contributions from its member banks such that, if no default occurs, the scheme is assumed to have $€ 7.7$ billion at its disposal at the end of the transition period.

Table 1. Moments of the $\operatorname{Gamma}(a, b)$ distribution

\begin{tabular}{|l|l|}
\hline \multicolumn{2}{|l|}{$\operatorname{Gamma}(a, b)$} \\
\hline mean & $\mathrm{a} / \mathrm{b}$ \\
\hline variance & $\mathrm{a} / \mathrm{b}^{2}$ \\
\hline skewness & $2 \mathrm{a}^{-1 / 2}$ \\
\hline kurtosis & $3\left(1+2 \mathrm{a}^{-1}\right)$ \\
\hline
\end{tabular}

Table 2. One-to-one correspondence between historical and risk-neutral default probabilities

\begin{tabular}{|l|c|c|c|c|c|c|c|}
\hline Rating & Aaa & Aa1 & Aa2 & Aa3 & A1 & A2 & A3 \\
\hline$D P^{Q}$ & $0.0975 \%$ & $0.1196 \%$ & $0.1265 \%$ & $0.1558 \%$ & $0.1976 \%$ & $0.3053 \%$ & $0.4957 \%$ \\
\hline$D P^{P}$ & $0.0022 \%$ & $0.0038 \%$ & $0.0067 \%$ & $0.0116 \%$ & $0.0201 \%$ & $0.0348 \%$ & $0.0604 \%$ \\
\hline
\end{tabular}

Data sources: Emery et al (2008), Moody's and Bloomberg

Table 3. Financial indicators for the regression model

\begin{tabular}{|c|c|}
\hline ROAA & $\frac{\text { Exc. Capital }}{\text { Total Assets }}$ \\
\hline$\frac{\text { Liquid Assets }}{\text { Customer \& ST Funding }}$ & $\frac{\text { Exc. Capital }}{\text { Risk-weighted Assets }}$ \\
\hline$\frac{\text { Net Loans }}{\text { Customer \& ST Funding }}$ & $\frac{\text { Loan Loss Provisions }}{\text { Net interest Revenue }}$ \\
\hline Cost to income & $\frac{\text { Loan Loss Provisions }}{\text { Operating Income }}$ \\
\hline
\end{tabular}

Data source: Bankscope 
Table 4. One year loss distribution of the banking system; the banks' underlying asset-value process follows a one-factor Gaussian model

(a) One year Italian sample banks' loss distribution (b) One year Italian sample banks' conditional loss distribution

\begin{tabular}{|l|r|}
\hline Percentile & Loss (million $€$ ) \\
\hline $95.00 \%$ & 0 \\
\hline $95.85 \%$ & 0 \\
\hline $95.86 \%$ & 2 \\
\hline $97.65 \%$ & 2217 \\
\hline $97.66 \%$ & 2319 \\
\hline $98.00 \%$ & 3070 \\
\hline $98.81 \%$ & 7645 \\
\hline $98.82 \%$ & 7787 \\
\hline $99.00 \%$ & 13003 \\
\hline $99.90 \%$ & 67040 \\
\hline $99.99 \%$ & 127014 \\
\hline $100.00 \%$ & 162202 \\
\hline
\end{tabular}

\begin{tabular}{|l|r|}
\hline \multicolumn{1}{|c|}{ Percentile } & Loss (million $€$ ) \\
\hline $25.0 \%$ & 586 \\
\hline $50.0 \%$ & 2873 \\
\hline $71.3 \%$ & 7659 \\
\hline $71.4 \%$ & 7723 \\
\hline $75.0 \%$ & 11283 \\
\hline $90.0 \%$ & 30911 \\
\hline $95.0 \%$ & 44683 \\
\hline $99.0 \%$ & 91913 \\
\hline $99.9 \%$ & 136991 \\
\hline $100.0 \%$ & 162202 \\
\hline
\end{tabular}

Table 5. One year empirical loss distribution of the DGS corresponding to the employed sample; the banks' underlying asset-value process follows a one-factor Gaussian model

(a) One year DGS loss distribution

\begin{tabular}{|l|r|}
\hline Percentile & Loss (million $€$ ) \\
\hline $95.00 \%$ & 0 \\
\hline $98.81 \%$ & 0 \\
\hline $98.82 \%$ & 120 \\
\hline $99.00 \%$ & 5335 \\
\hline $99.90 \%$ & 59372 \\
\hline $99.99 \%$ & 119347 \\
\hline $100.00 \%$ & 154534 \\
\hline
\end{tabular}

(b) One year DGS conditional loss distribution

\begin{tabular}{|l|r|}
\hline \multicolumn{1}{|c|}{ Percentile } & Loss (million $€$ ) \\
\hline $10.00 \%$ & 2879 \\
\hline $25.00 \%$ & 8370 \\
\hline $50.00 \%$ & 14982 \\
\hline $75.00 \%$ & 29044 \\
\hline $90.00 \%$ & 53103 \\
\hline $95.00 \%$ & 71466 \\
\hline $99.00 \%$ & 118362 \\
\hline $99.90 \%$ & 149465 \\
\hline $100.00 \%$ & 154534 \\
\hline
\end{tabular}

Table 6. One year empirical loss distribution of the banking system; the banks' underlying asset-value process follows a one-factor Shifted Gamma Lévy model

(a) One year Italian sample banks' loss distribution

\begin{tabular}{|l|l|}
\hline Percentile & Loss (million $€$ ) \\
\hline $95.00 \%$ & 0 \\
\hline $95.09 \%$ & 0 \\
\hline $95.10 \%$ & 5 \\
\hline $97.93 \%$ & 2098 \\
\hline $97.94 \%$ & 2341 \\
\hline $98.00 \%$ & 2341 \\
\hline $99.00 \%$ & 6080 \\
\hline $99.17 \%$ & 7437 \\
\hline $99.18 \%$ & 7750 \\
\hline $99.90 \%$ & 99280 \\
\hline $99.99 \%$ & 166440 \\
\hline $100.00 \%$ & 166440 \\
\hline
\end{tabular}

(b) One year Italian sample banks' conditional loss distribution

\begin{tabular}{|l|r|}
\hline Percentile & Loss (million $€$ ) \\
\hline $25.0 \%$ & 442 \\
\hline $50.0 \%$ & 1046 \\
\hline $75.0 \%$ & 3615 \\
\hline $83.2 \%$ & 7642 \\
\hline $83.3 \%$ & 7770 \\
\hline $90.0 \%$ & 16689 \\
\hline $95.0 \%$ & 31419 \\
\hline $99.0 \%$ & 164455 \\
\hline $99.9 \%$ & 166440 \\
\hline $100.0 \%$ & 166440 \\
\hline
\end{tabular}


Table 7. One year empirical loss distribution of the DGS corresponding to the employed sample; the banks' underlying asset-value process follows a one-factor Shifted Gamma Lévy model

(a) One year DGS loss distribution

\begin{tabular}{|l|r|}
\hline Percentile & Loss (million $€$ ) \\
\hline $95.00 \%$ & 0 \\
\hline $99.00 \%$ & 0 \\
\hline $99.17 \%$ & 0 \\
\hline $99.18 \%$ & 82 \\
\hline $99.90 \%$ & 91612 \\
\hline $99.99 \%$ & 158773 \\
\hline $100.00 \%$ & 158773 \\
\hline
\end{tabular}

(b) One year DGS conditional loss distribution

\begin{tabular}{|l|r|}
\hline Percentile & Loss (million $€$ ) \\
\hline $10.00 \%$ & 5324 \\
\hline $25.00 \%$ & 8370 \\
\hline $50.00 \%$ & 13413 \\
\hline $75.00 \%$ & 28470 \\
\hline $90.00 \%$ & 126152 \\
\hline $95.00 \%$ & 156835 \\
\hline $99.00 \%$ & 158773 \\
\hline $99.90 \%$ & 158773 \\
\hline $100.00 \%$ & 158773 \\
\hline
\end{tabular}

Table 8. 10 years empirical loss distribution of the banking system

(a) Italian sample banks' loss distribution

\begin{tabular}{|l|r|}
\hline Percentile & Loss (million $€$ ) \\
\hline $75.00 \%$ & 0 \\
\hline $77.62 \%$ & 0 \\
\hline $77.63 \%$ & 5 \\
\hline $80.00 \%$ & 442 \\
\hline $85.00 \%$ & 2271 \\
\hline $90.00 \%$ & 7315 \\
\hline $90.29 \%$ & 7656 \\
\hline $90.30 \%$ & 7676 \\
\hline $95.00 \%$ & 26414 \\
\hline $99.00 \%$ & 86343 \\
\hline $99.90 \%$ & 154879 \\
\hline $99.99 \%$ & 166409 \\
\hline $100.00 \%$ & 166440 \\
\hline
\end{tabular}

(b) Italian sample banks' conditional loss distribution

\begin{tabular}{|l|l|}
\hline \multicolumn{1}{|c|}{ Percentile } & \multicolumn{1}{c|}{ Loss (million $€$ ) } \\
\hline $25.0 \%$ & 1040 \\
\hline $50.0 \%$ & 4968 \\
\hline $56.6 \%$ & 7656 \\
\hline $56.7 \%$ & 7708 \\
\hline $75.0 \%$ & 23364 \\
\hline $90.0 \%$ & 53416 \\
\hline $95.0 \%$ & 81981 \\
\hline $99.0 \%$ & 136236 \\
\hline $99.9 \%$ & 165441 \\
\hline $100.0 \%$ & 166440 \\
\hline
\end{tabular}

Table 9. 10 years empirical loss distribution of the DGS corresponding to the employed sample

(a) DGS loss distribution

\begin{tabular}{|l|r|}
\hline Percentile & Loss (million $€$ ) \\
\hline $90.00 \%$ & 0 \\
\hline $90.29 \%$ & 0 \\
\hline $90.30 \%$ & 9 \\
\hline $95.00 \%$ & 18747 \\
\hline $99.00 \%$ & 78675 \\
\hline $99.90 \%$ & 147212 \\
\hline $99.99 \%$ & 158742 \\
\hline $100.00 \%$ & 158773 \\
\hline
\end{tabular}

(b) DGS conditional loss distribution

\begin{tabular}{|l|r|}
\hline \multicolumn{1}{|c|}{ Percentile } & Loss (million $€$ ) \\
\hline $10.00 \%$ & 3201 \\
\hline $25.00 \%$ & 8955 \\
\hline $50.00 \%$ & 19650 \\
\hline $75.00 \%$ & 42572 \\
\hline $90.00 \%$ & 79894 \\
\hline $95.00 \%$ & 106916 \\
\hline $99.00 \%$ & 148221 \\
\hline $99.90 \%$ & 158760 \\
\hline $100.00 \%$ & 158773 \\
\hline
\end{tabular}




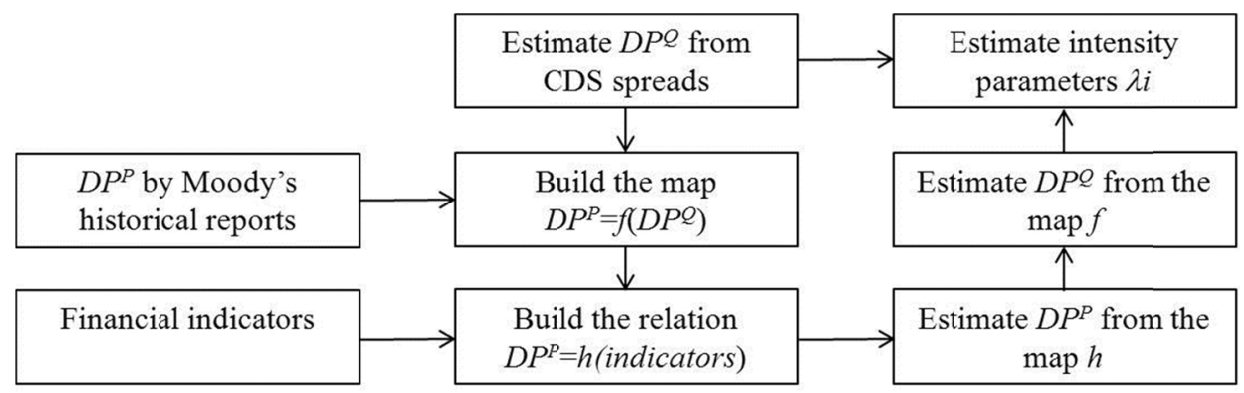

Figure 1. Procedure for the estimation of banks' probabilities

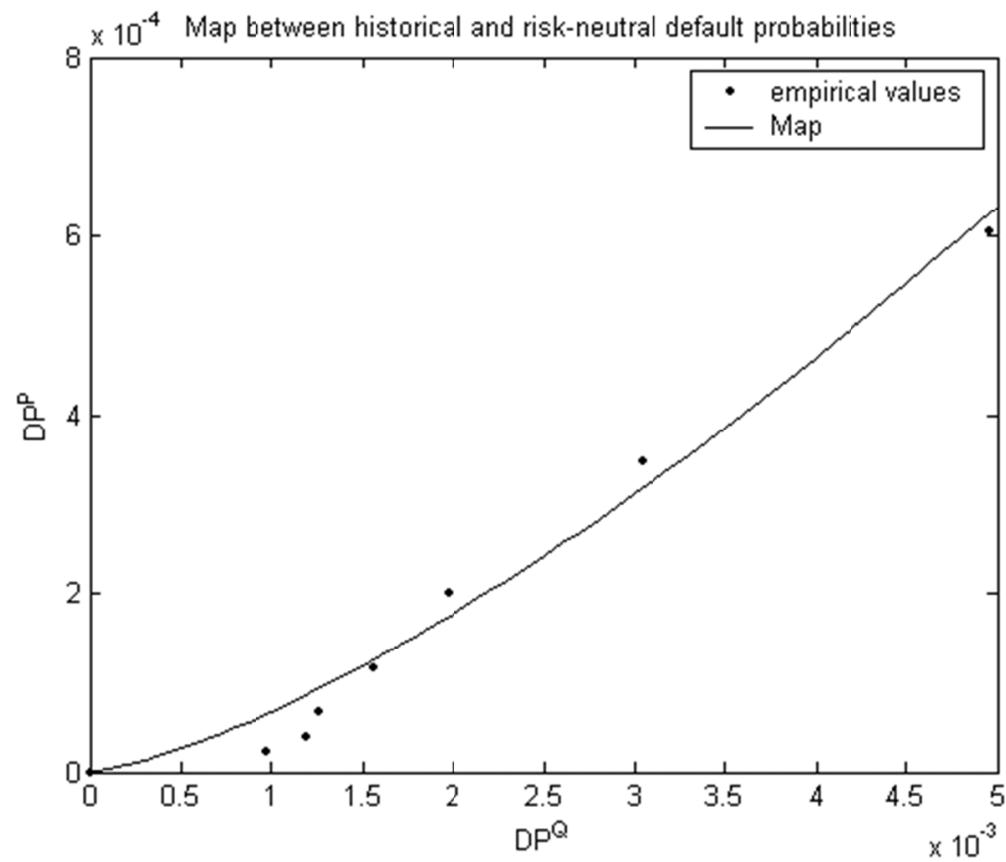

Figure 2. Map between risk-neutral and historical default probabilities 


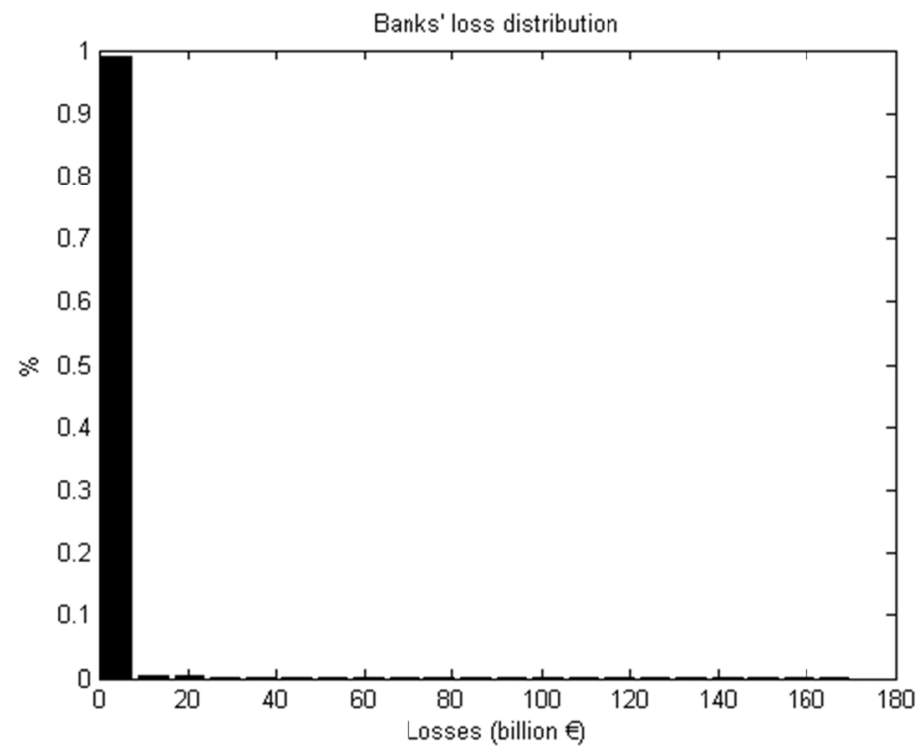

(a) Banking system's loss distribution

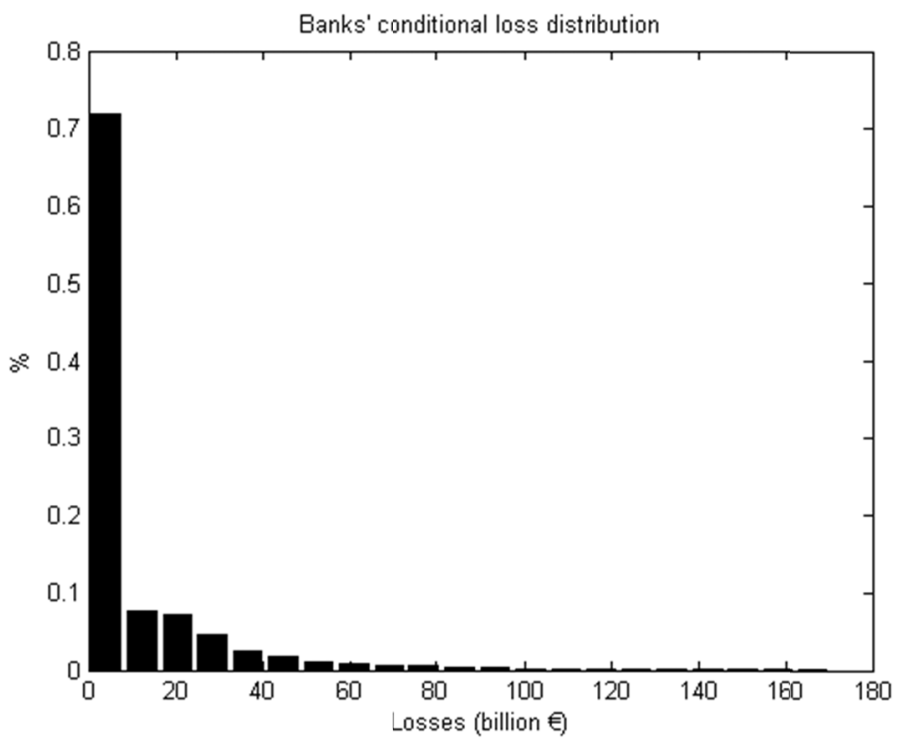

(b) Banking system's conditional loss distribution

Figure 3. One year empirical loss distribution of the banking system; the banks' underlying asset-value process follows a one-factor Gaussian model 


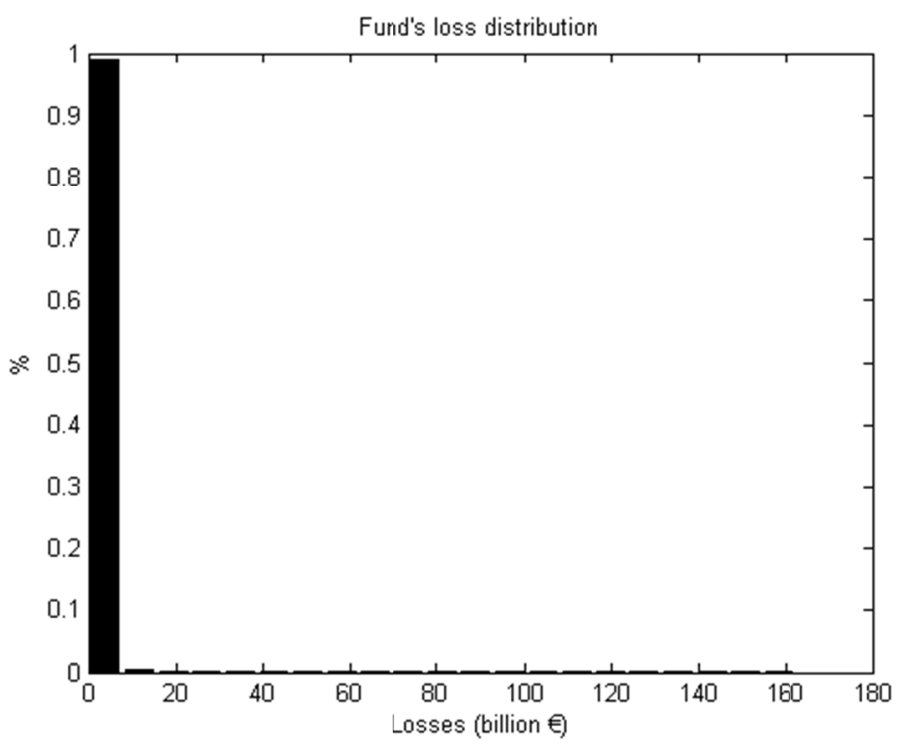

(a) DGS loss distribution

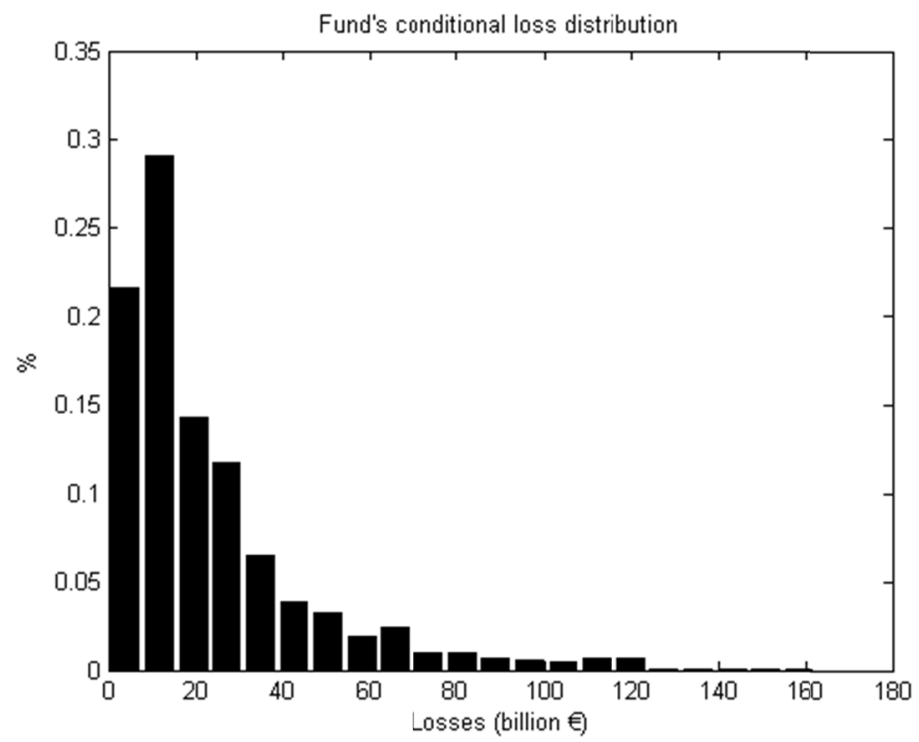

(b) DGS conditional loss distribution

Figure 4. One year empirical loss distribution of the DGS corresponding to the employed sample; the banks' underlying asset-value process follows a one-factor Gaussian model 


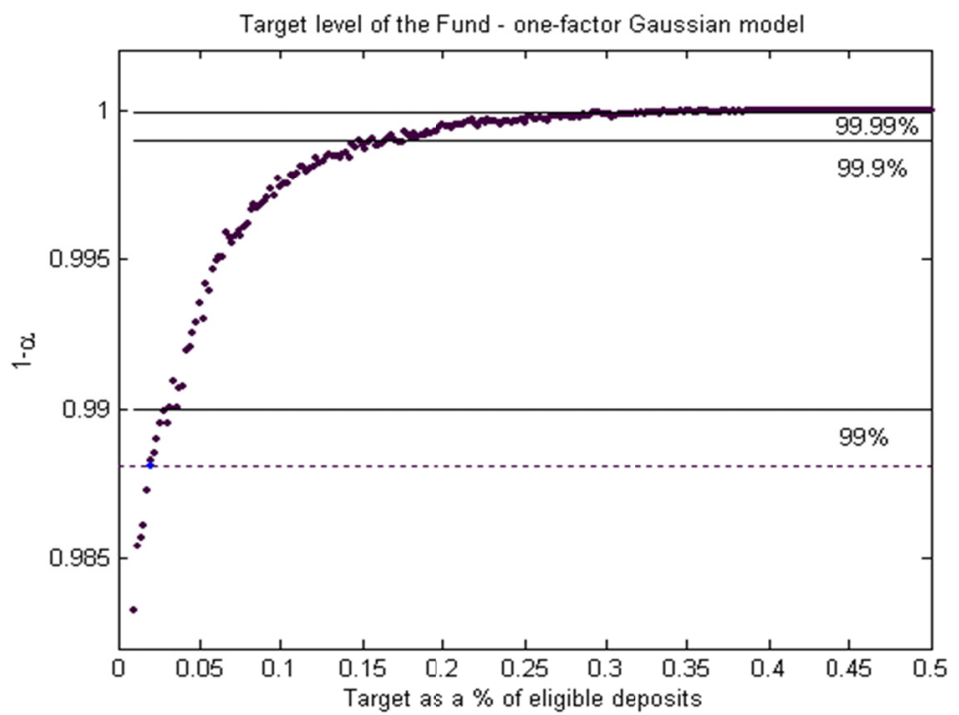

Figure 5. Optimum target; the banks' underlying asset-value process follows a one-factor Gaussian model

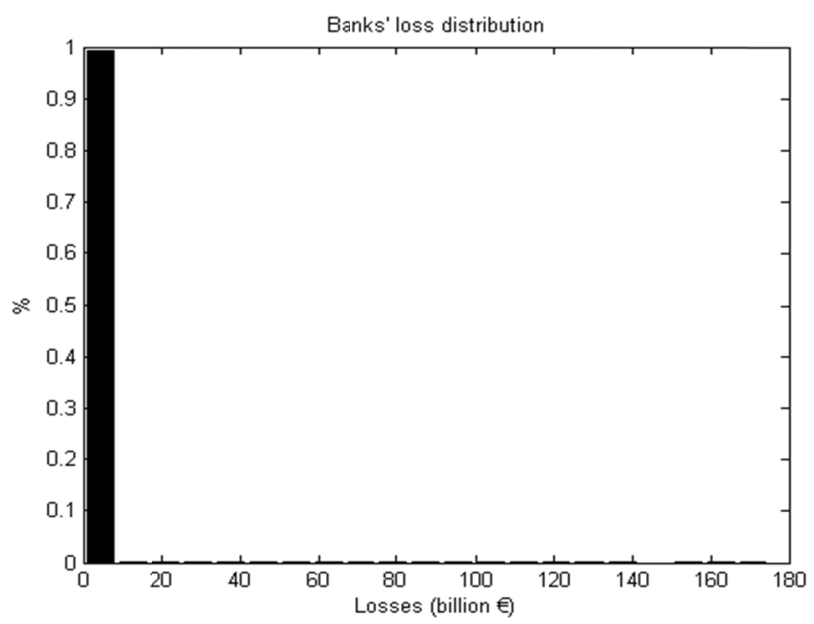

(a) Banking system's loss distribution

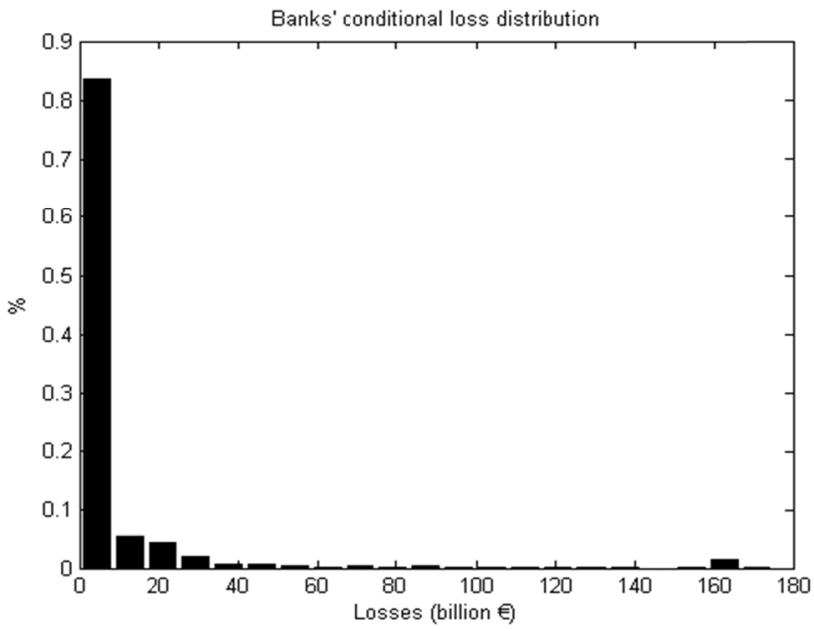

(b) Banking system's conditional loss distribution

Figure 6. One year empirical loss distribution of the banking system; the banks' underlying asset-value process follows a one-factor Shifted Gamma Lévy model 


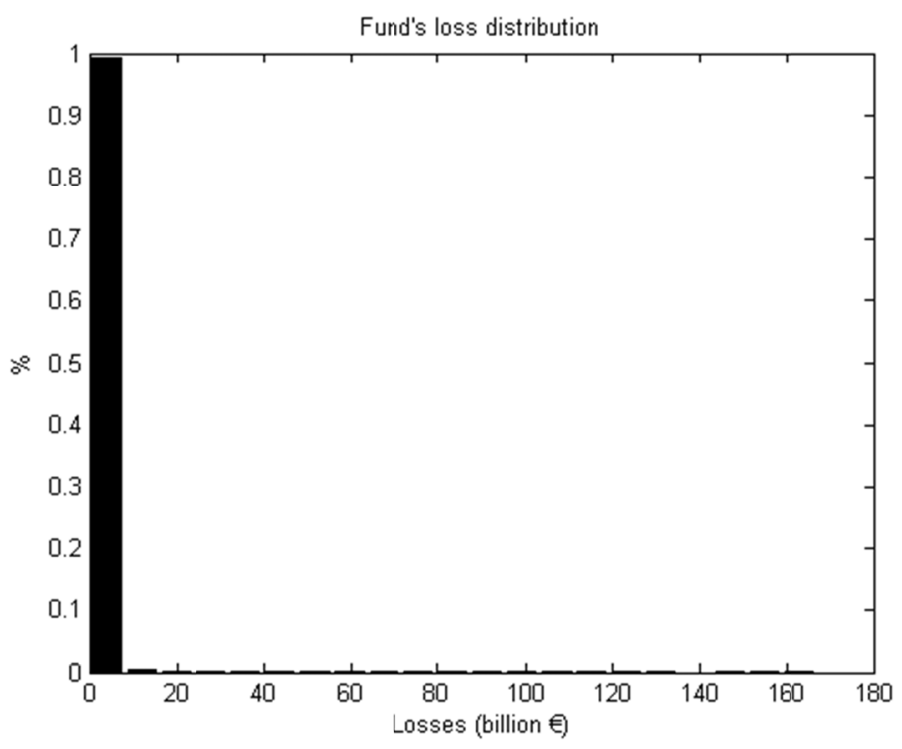

(a) DGS loss distribution

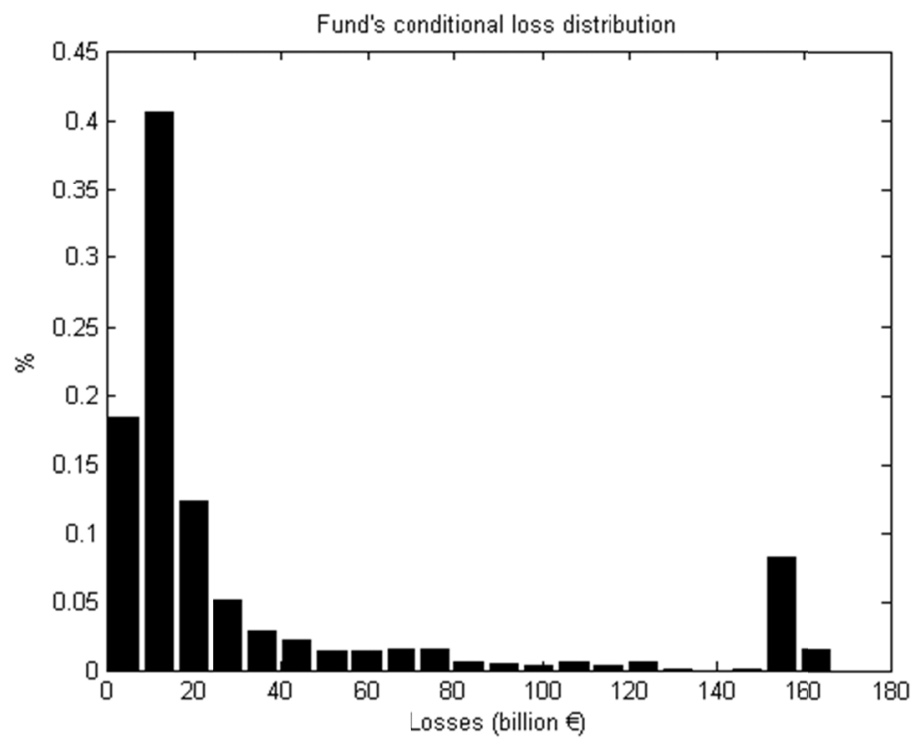

(b) DGS conditional loss distribution

Figure 7. One year empirical loss distribution of the Italian DGS corresponding to the employed sample; the banks' underlying asset-value process follows a one-factor Shifted Gamma Lévy model 


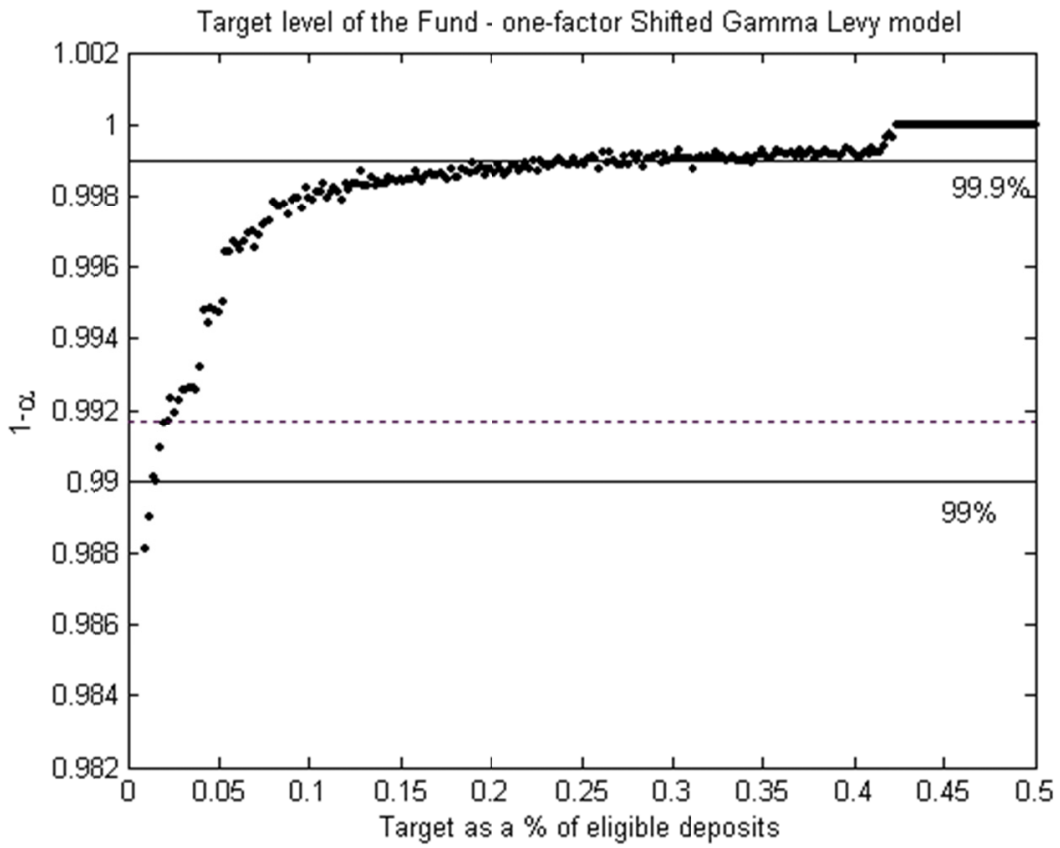

Figure 8. Optimum target; the banks' underlying asset-value process follows a one-factor Shifted Gamma Lévy model

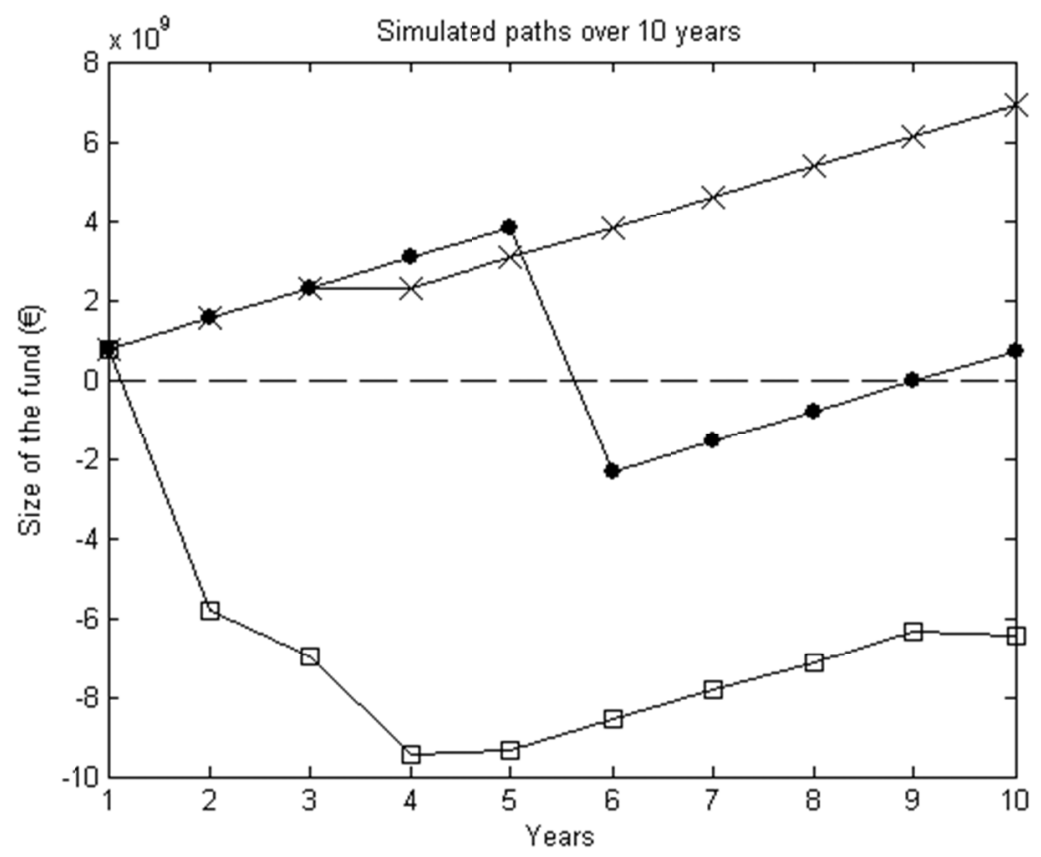

Figure 9. Simulated paths for the fund 


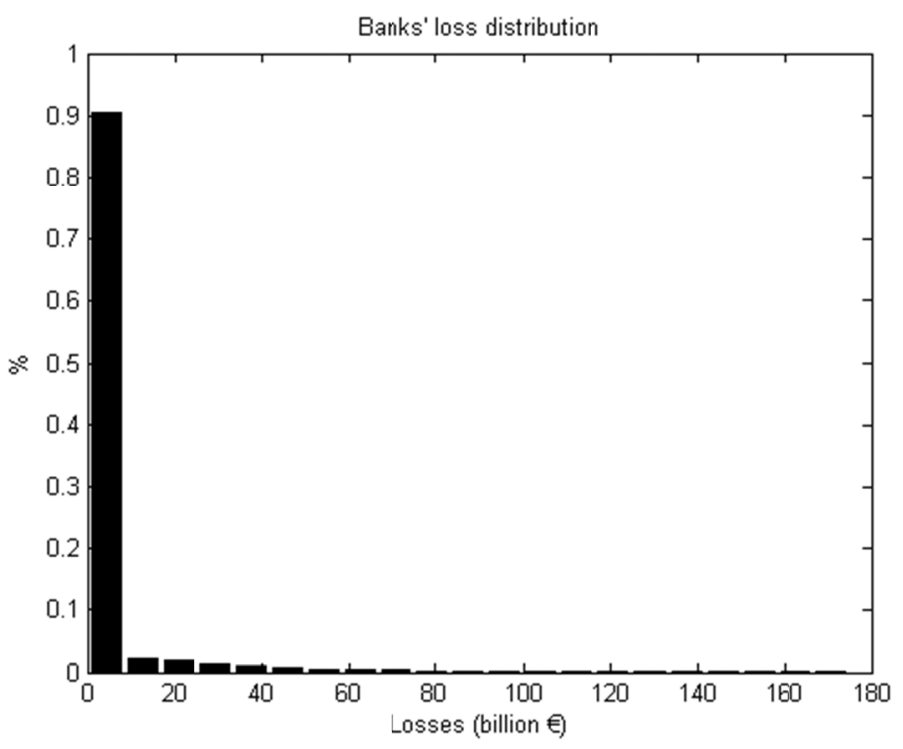

(a) Banking system's loss distribution

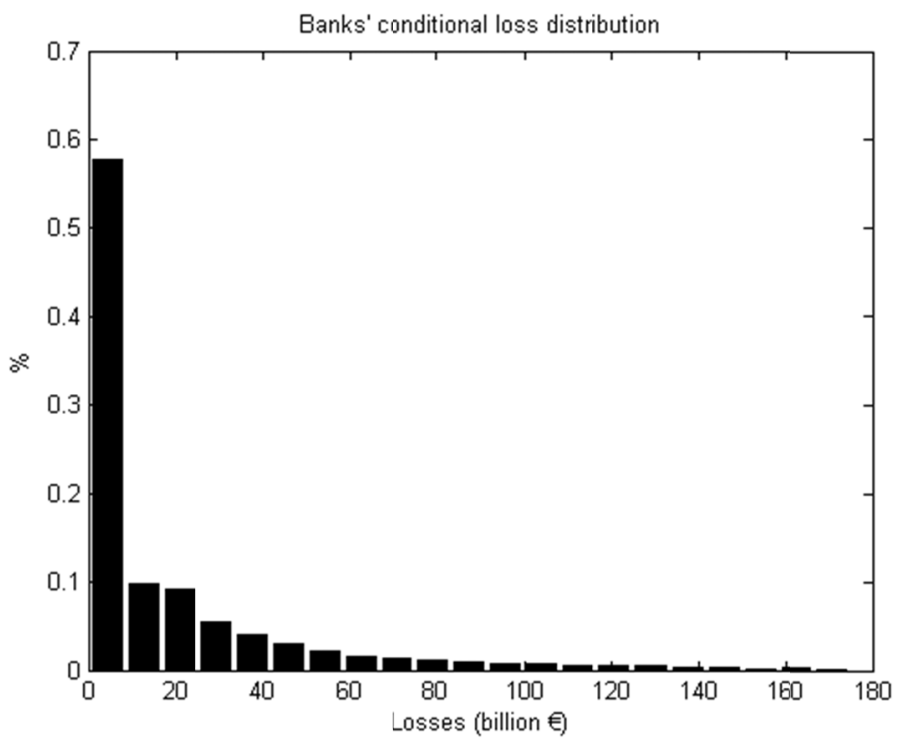

(b) Banking system's conditional loss distribution

Figure 10. 10 years empirical loss distribution of the banking system 


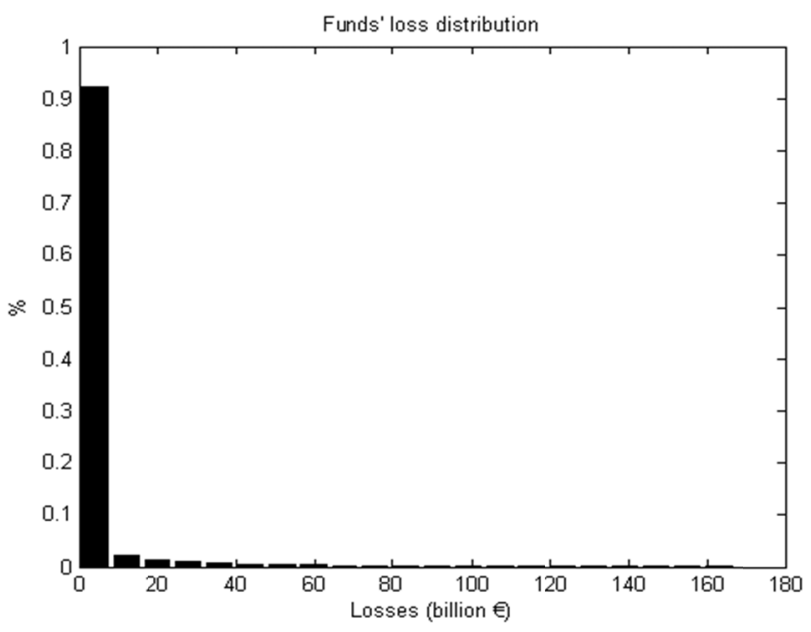

(a) DGS loss distribution

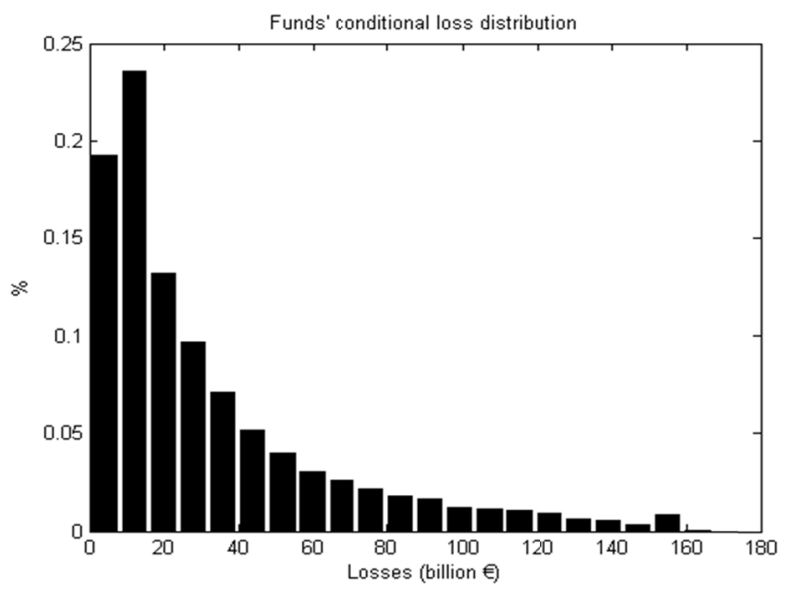

(b) DGS conditional loss distribution

Figure 11. 10 years empirical loss distribution of the DGS corresponding to the employed sample

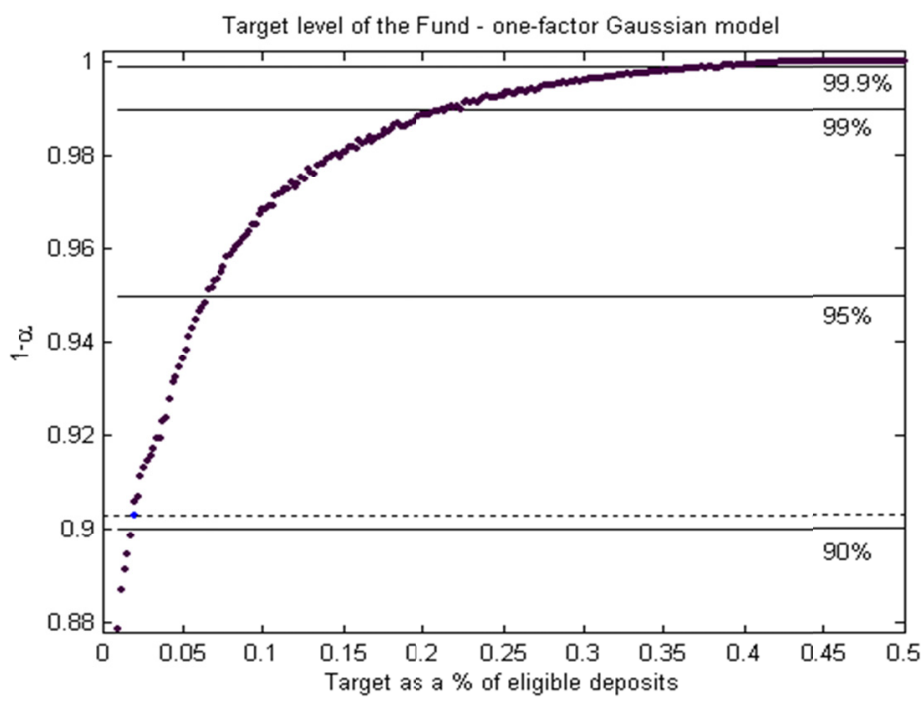

Figure 12. Optimum target 


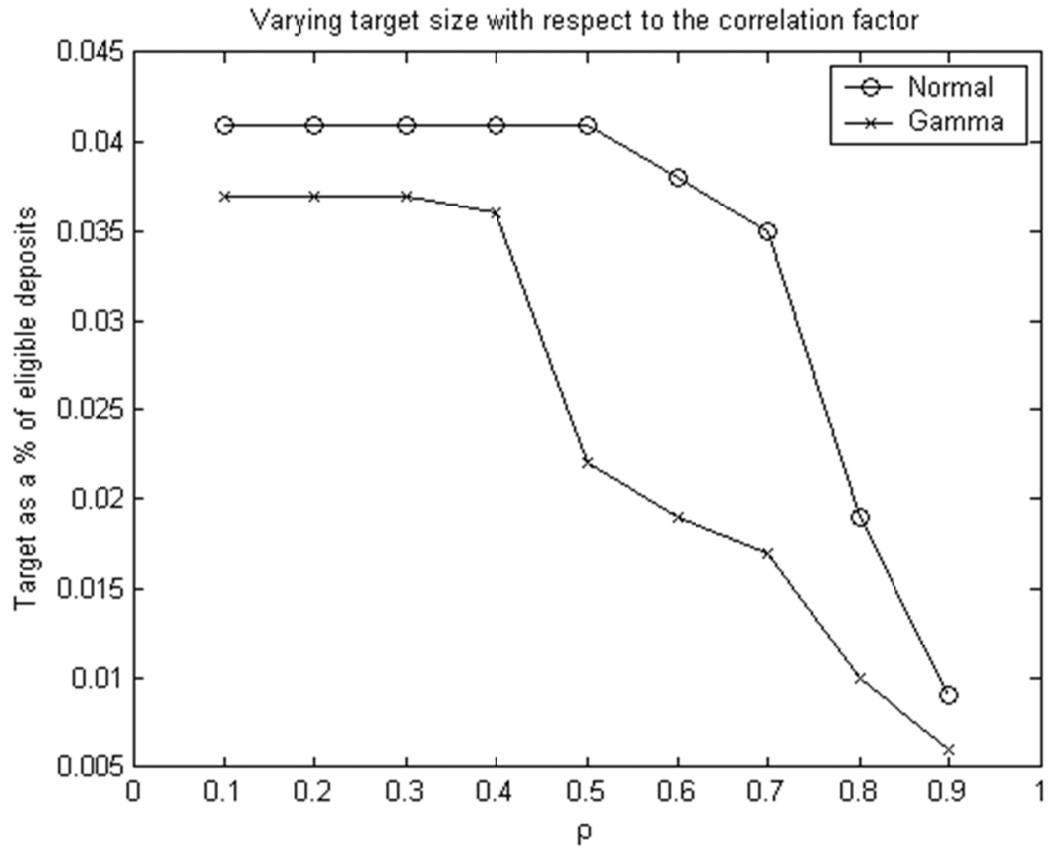

Figure 13. Results of the sensitivity exercise. Variation of the target size with respect to the correlation factor. The target is computed assuming that $99 \%$ of losses must be covered

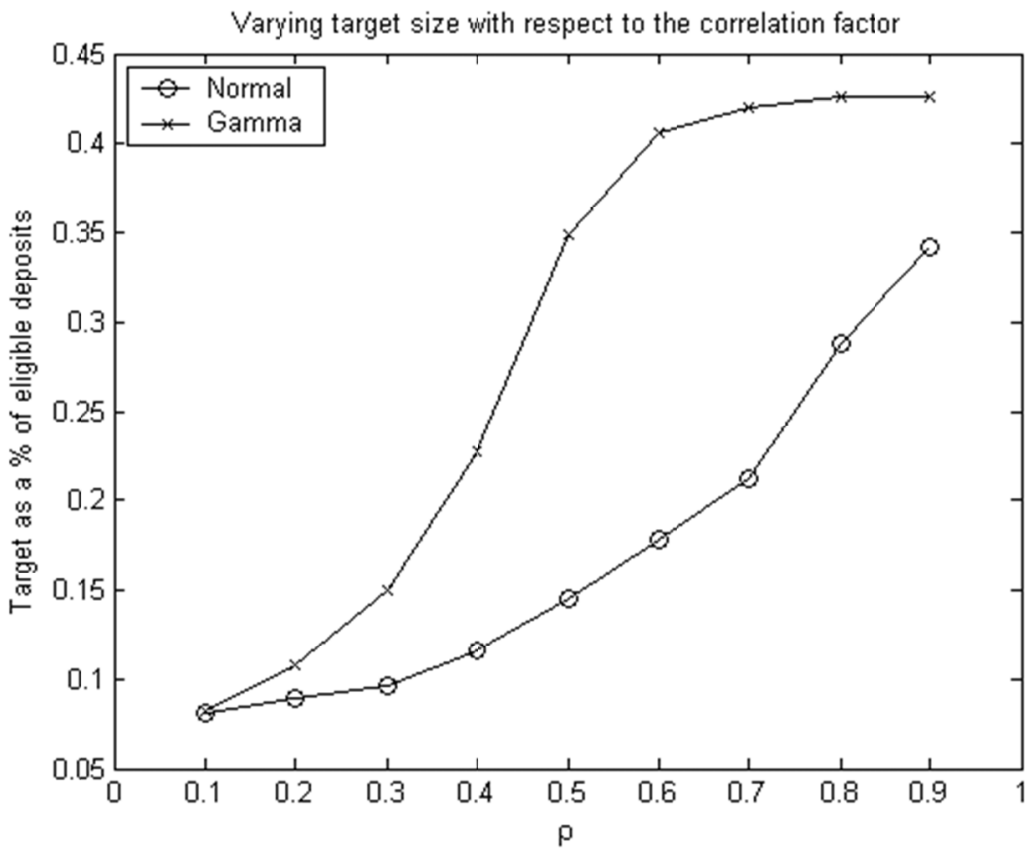

Figure 14. Results of the sensitivity exercise. Variation of the target size with respect to the correlation factor. The target is computed assuming that $99.95 \%$ of losses must be covered 